\title{
Implication of Interleukin-12/15/18 and Ruxolitinib in the Phenotype, Proliferation, and Polyfunctionality of Human Cytokine-Preactivated Natural Killer Cells
}

\begin{abstract}
Iñigo Terrén', Idoia Mikelez',2, Irati Odriozola', Andrea Gredilla', Javier González', Ane Orrantia1, Joana Vitallé', Olatz Zenarruzabeitia ${ }^{1}$ and Francisco Borrego $0^{1,3,4 *}$

'Immunopathology Group, BioCruces Health Research Institute, Barakaldo, Spain, ${ }^{2} \mathrm{ClC}$ biomaGUNE, Donostia-San Sebastián, Spain, ${ }^{3} / k e r b a s q u e$, Basque Foundation for Science, Bilbao, Spain, ${ }^{4}$ Basque Center for Transfusion and Human Tissues, Galdakao, Spain
\end{abstract}

A brief in vitro stimulation of natural killer (NK) cells with interleukin (IL)-12, IL-15, and
OPEN ACCESS

Edited by:

Miguel López-Botet,

Institut Hospital del Mar

d'Investigacions Mèdiques, Spain

Reviewed by:

Ennio Carbone,

Magna Graecia University, Italy

Amir Horowitz,

Icahn School of Medicine at

Mount Sinai, United States

${ }^{*}$ Correspondence:

Francisco Borrego

francisco.borregorabasco@ osakidetza.eus

Specialty section:

This article was submitted

to NK and Innate

Lymphoid Cell Biology,

a section of the journal

Frontiers in Immunology

Received: 01 February 2018

Accepted: 26 March 2018

Published: 16 April 2018

Citation:

Terrén I, Mikelez I, Odriozola I, Gredilla A, González J, Orrantia A, Vitallé J, Zenarruzabeitia $O$ and Borrego F (2018) Implication of Interleukin-12/15/18 and Ruxolitinib in the Phenotype, Proliferation, and Polyfunctionality of Human

Cytokine-Preactivated Natural Killer Cells.

Front. Immunol. 9:737. doi: 10.3389/fimmu.2018.00737 IL-18 endow them a memory-like behavior, characterized by higher effector responses when they are restimulated after a resting period of time. These preactivated NK cells, also known as cytokine-induced memory-like (CIML) NK cells, have several properties that make them a promising tool in cancer immunotherapy. In the present study, we have described the effect that different combinations of IL-12, IL-15, and IL-18 have on the generation of human CIML NK cells. Our data points to a major contribution of IL-15 to CIML NK cell-mediated cytotoxicity against target cells. However, the synergistic effect of the three cytokines grant them the best polyfunctional profile, that is, cells that simultaneously degranulate (CD107a) and produce multiple cytokines and chemokines such as interferon $\gamma$, tumor necrosis factor $\alpha$, and $\mathrm{C}-\mathrm{C}$ motif chemokine ligand 3. We have also analyzed the involvement of each cytokine and their combinations in the expression of homing receptors CXCR4 and CD62L, as well as the expression of CD25 and IL-2-induced proliferation. Furthermore, we have tested the effects of the Jak1/2 inhibitor ruxolitinib in the generation of CIML NK cells. We found that ruxolitinib-treated CIML NK cells expressed lower levels of CD25 than non-treated CIML NK cells, but exhibited similar proliferation in response to IL-2. In addition, we have also found that ruxolitinib-treated NK cells displayed reduced effector functions after the preactivation, which can be recovered after a 4 days expansion phase in the presence of low doses of IL-2. Altogether, our results describe the impact that each cytokine and the Jak $1 / 2$ pathway have in the phenotype, IL-2-induced proliferation, and effector functions of human CIML NK cells.

Keywords: natural killer cells, ruxolitinib, memory-like natural killer cells, cytokine preactivation, cytokine production, polyfunctionality, degranulation

\section{INTRODUCTION}

Natural killer (NK) cells are innate lymphocytes with a crucial role in the defense against transformed cells and viral infections. They perform their work through different processes such as cell-mediated cytotoxicity and secretion of cytokines and chemokines including interferon (IFN) $\gamma$, tumor necrosis factor (TNF) $\alpha$, and C-C motif chemokine ligand (CCL)3 (1-4). Human NK cells 
are defined by the expression of CD56 (natural cell adhesion molecule) and the lack of CD3/TCR (T cell receptor) complex $(1,3)$. The activation of NK cells is controlled by a balance between signals from inhibitory and activating receptors $(5,6)$. Among the firsts, there are major histocompatibility complex (MHC) class I-specific receptors such as the highly polymorphic inhibitory killer immunoglobulin-like receptors (KIRs) that bind to MHC class Ia ligands (HLA-A, $-\mathrm{B}$, and $-\mathrm{C}$ ), and the inhibitory CD94/NKG2A heterodimeric receptor that binds to MHC class Ib ligands (HLA-E). In addition, NK cells express other inhibitory receptors such as CD300a, TIGIT, LAIR-1, etc. $(4,7,8)$. On the other side, NK cells express a wide repertoire of activating receptors, including the natural cytotoxicity receptors $(\mathrm{NKp} 30$, NKp44, NKp46), C-type lectin-like receptors (CD94/NKG2C, CD94/NKG2E, and the homodimer NKG2D), activating KIRs, the antibody-binding receptor CD16 (or FcyRIIIa), DNAM-1, 2B4, NKp80, CD300c, etc. $(1,4,5,9,10)$.

Although NK cells have been traditionally classified as part of the innate immune system, recent publications have shown that they exhibit several immunological memory features. The first evidence of the existence of memory NK cells was described in mice lacking $\mathrm{T}$ and $\mathrm{B}$ cells. They developed long lasting and specific contact hypersensitivity responses to different haptens that were mediated by NK cells (11). Later, it was demonstrated that mouse NK cells also exhibited specific memory responses to mouse cytomegalovirus (12), vaccinia virus (13), and to vaccines containing antigens from influenza virus, vesicular stomatitis virus, or human immunodeficiency virus (HIV) (14). In non-human primates, it has been described antigen specific NK cell memory responses in chronically simian-human immunodeficiency virus and simian immunodeficiency virusinfected rhesus macaques, and also in animals vaccinated with replication-incompetent adenovirus vector (Ad26) expressing HIV-1 Env or DNA-Ad26 prime-boost vaccine expressing $\mathrm{SIV}_{\text {mac239 }} \mathrm{Gag}(15)$. In humans, infection by human cytomegalovirus (HCMV) promotes an adaptive expansion of long-lived NK cells that are characterized by the expression of the CD94/ NKG2C receptor (16-18). These adaptive NKG2C+ NK cells exhibit higher effector functions than canonical NKG2CNK cells and have been associated with the control of HCMV infection in kidney transplant recipients and with protection from leukemia relapse after allogeneic hematopoietic stem cell transplantation (HSCT) (17, 19-24). Furthermore, exposure of NK cells to a combination of interleukin (IL)-12, IL-15 plus IL-18 for a short period of time (16-18 h) results in a memorylike behavior in the absence of antigen. These cytokine-induced memory-like (CIML) NK cells are characterized by enhanced effector functions after a resting period of time (25-27). For example, human CIML NK cells exhibit greater IFN $\gamma$ and TNF $\alpha$ production, increased expression of granzyme B and perforin, and superior cytotoxicity in response to tumor targets in vitro (27-31). Furthermore, in xenograft mouse models, CIML NK cells were found to be effective $(26,27)$.

Natural killer cells are of obvious clinical interest, and they are currently being explored as a potent tool for the treatment of hematological malignancies (32-34). One of the first clinical observations that demonstrated the relevant role of NK cells in the fight against cancer was the appreciation that in patients with acute myeloid leukemia (AML) that were subjected to an allogeneic HSCT, the success of it was greater when donor subsets of NK cells possessed a KIR repertoire that do not interact with HLA class I molecules in the recipient. In this way, these alloreactive NK cells can exert a graft-versus-leukemia effect in the absence of graft-versus-host disease (35). The ability of human NK cells to lyse leukemic cells in vivo in the context of patients who undergo HSCT, demonstrates that NK cells participate in the immunosurveillance against the development of leukemias. However, despite recent progress, there are still many patients with a poor prognosis. In these cases, adoptive NK cell therapy could offer a relatively safe and effective alternative. In fact, many clinical trials with NK cell infusions have been completed or are underway $(34,36-38)$. Interestingly, there are several ongoing clinical trials using CIML NK cells (27) (NCT01898793, NCT03068819, and NCT02782546).

In this work, we have studied the contribution of each cytokine (IL-12, IL-15, and IL-18) to the phenotype, proliferation, and polyfunctionality of human CIML NK cells. Furthermore, considering that IL-12 and IL-15 induced signals involve Jak2 and Tyk 2 and Jak1/3 pathways, respectively, we decided to investigate the role of the specific Jak1/2 inhibitor ruxolitinib, a drug that has been approved for the treatment of myelofibrosis, in the generation of CIML NK cells. Altogether, our results may contribute to a better knowledge about human CIML NK cells and their properties.

\section{MATERIALS AND METHODS}

\section{Subjects and Samples}

Blood samples from adult healthy donors were collected through the Basque Biobank for Research (http://www.biobancovasco.org). The Basque Biobank complies with the quality management, traceability, and biosecurity, set out in the Spanish Law 14/2007 of Biomedical Research and in the Royal Decree 1716/2011. All subjects provided written and signed informed consent in accordance with the Declaration of Helsinki. The protocol was approved by the Basque Ethics Committee for Clinical Research (PI + INC-BIOEF 2014-02 14-27 and PI2014079). As indicated in each figure legend, samples from 4 to 8 different donors were used for each set of experiments.

\section{Antibodies and Reagents}

The following fluorochrome conjugated mouse anti-human mAbs were used for flow cytometric analysis: PE anti-CD25 (M-A251), APC-Cy7 anti-CD184/CXCR4 (12G5), PerCP-Cy5.5 anti-TNFo (MAb11), PerCP-Cy5.5 anti-CD3 (SK7), APC antiTNF $\alpha$ (MAb11), APC anti-CD56 (MEM-188), PE anti-CD56 (MEM-188), BV510 anti-CD56 (5.1H11) from BioLegend; PE-Cy7 anti-CD3 (SK7), PE-Cy7 anti-CD184/CXCR4 (12G5), PE-Cy7 anti-IFN $\gamma$ (B27), BV510 anti-IFN $\gamma$ (B27), BV510 antiCD62L (DREG-56), BV421 anti-CD107a (H4A3), PE anti-CD16 (3G8), Pacific Blue mouse anti-signal transducer and activator of transcription (STAT)5(pY694) (47/Stat5(pY694)) from BD Biosciences; and PE anti-CCL3 (MIP-1 alpha), APC-Cy7 
anti-CD3 (SK7) from eBioscience. For flow cytometric analyses were also used LIVE/DEAD ${ }^{\text {TM }}$ Fixable Near-IR Dead Cell Stain Kit (Invitrogen) and CellTrace ${ }^{\mathrm{TM}}$ CFSE Cell Proliferation Kit (Thermo Fisher Scientific).

The following reagents were also used: recombinant human IL-12 (Miltenyi Biotec), recombinant human IL-15 (Miltenyi Biotec), recombinant human IL-18 (MBL International), recombinant human IL-2 (Miltenyi Biotec), Jak1/2 inhibitor ruxolitinib (INCB018424, Selleckchem), BD GolgiStop ${ }^{\text {TM }}$ Protein Transport Inhibitor (monensin), BD GolgiPlug ${ }^{\mathrm{TM}}$ Protein Transport Inhibitor (brefeldin A), BD Cytofix/Cytoperm ${ }^{\mathrm{TM}}$ Plus Kit (including Fixation/Permeabilization solution and BD Perm/Wash ${ }^{\mathrm{TM}}$ Buffer), BD Cytofix Fixation Buffer, BD Phosflow ${ }^{\text {TM }}$ Perm Buffer III, Brilliant Buffer (BD Biosciences), paraformaldehyde (SigmaAldrich), calcein AM (Life Technologies), and Triton ${ }^{\mathrm{TM}} \mathrm{X}-100$ (Sigma-Aldrich).

\section{Cell Isolation and Cell Culture}

Fresh peripheral blood mononuclear cells (PBMCs) were obtained from buffy coats by ficoll (GE Healthcare) density centrifugation. Isolated PBMCs were cultured at $37^{\circ} \mathrm{C}$ in Iscove's Modified Dulbecco's Medium (IMDM) (Thermo Fisher Scientific) supplemented with 10\% human AB serum (Invitrogen), 1\% GlutaMax (Thermo Fisher Scientific), and $1 \%$ penicillin/ streptavidin (Thermo Fisher Scientific), hereinafter, complete IMDM or cIMDM. PBMCs were plated at $2 \times 10^{6} \mathrm{cell} / \mathrm{mL}$ in 24-well plates and cultured at $37^{\circ} \mathrm{C}$ in cIMDM for $16-18 \mathrm{~h}$ (preactivation phase) with IL-12, IL-15, and/or IL-18 (10, 100, and $50 \mathrm{ng} / \mathrm{mL}$, respectively) and in the presence and absence of $0.1-1 \mu \mathrm{M}$ ruxolitinib. Next, cells were washed three times with phosphate-buffered saline (PBS) and plated at $2 \times 10^{6} \mathrm{cell} / \mathrm{mL}$ in new 24 -well plates, and cultured at $37^{\circ} \mathrm{C}$ in cIMDM for 4 days (expansion phase) with 2-20 U/mL IL-2 (Figure 1).

\section{Calcein-AM-Based Cytotoxicity Assay}

This assay was performed following a previous published protocol (39). After the preactivation phase, PBMCs were washed twice with PBS. The target cell line K562 $\left(10^{6}\right.$ cells $\left./ \mathrm{mL}\right)$ was incubated in the presence of $15 \mu \mathrm{M}$ of calcein-AM for $30 \mathrm{~min}$ at $37^{\circ} \mathrm{C}$ in $\mathrm{cRPMI}$ (RPMI medium plus $10 \%$ fetal bovine serum, $1 \%$ penicillin/streptavidin, 1\% GlutaMax, 1\% non-essential aminoacids, and $1 \%$ sodium pyruvate). Then, target cells were washed twice. Calcein-AM labeled K562 cells (5,000 cells per well) were cocultured with PBMCs in $96 U$-bottom well plates for $3 \mathrm{~h}$ at $37^{\circ} \mathrm{C}$ at $10: 1$ and 5:1 effector:target (E:T) ratios. For the measurement of spontaneous release, K562 target cells were incubated with no PBMCs. Total released was achieved by adding 2\% Triton ${ }^{\mathrm{TM}} \mathrm{X}-100$ (Sigma-Aldrich) to the target cells. Triplicates were performed for all the conditions. After the incubation, $75 \mu \mathrm{L}$ of the supernatant were harvested and transferred to a black 96-well plate to measure calcein-AM release in a Fluoroskan Ascent (Thermo Fisher Scientific), with the excitation and the bandpass filters adjusted to $485 \pm 9$ and $538 \pm 9 \mathrm{~nm}$, respectively. The percentage of specific lysis was calculated with the following formula: $100 \times([($ Test release $)-($ Medium fluorescence $)]-[($ Spontaneous release $)-($ Medium fluorescence $)]) /$ $([($ Maximum release $)-($ Triton fluorescence $)]-[($ Spontaneous release) - (Medium fluorescence) $]$ ).

\section{Flow Cytometry Analysis}

For proliferation assays, $4 \times 10^{6} \mathrm{PBMCs} / \mathrm{mL}$ were labeled with $0.5 \mu \mathrm{M}$ CFSE before the preactivation phase following manufacturer's recommendations. For polyfunctionality analysis after the preactivation phase, PBMCs were incubated for $6 \mathrm{~h}$ at $37^{\circ} \mathrm{C}$ with Golgi Stop, Golgi Plug, and fluorochrome conjugated antiCD107a mAb. For polyfunctionality analysis after the expansion phase, PBMCs were also incubated in the presence and absence of K562 cells during $6 \mathrm{~h}$. Cells were washed twice with staining buffer containing PBS supplemented with $2.5 \%$ of bovine serum albumin, and stained for cell surface markers with the respective fluorochrome conjugated $\mathrm{mAbs}$ for $30 \mathrm{~min}$ on ice protected from light. For intracellular staining, cells were fixed and permeabilized with BD Cytofix/Cytoperm ${ }^{\mathrm{TM}}$ Plus Kit following the manufacturer's protocol. For analysis after the expansion

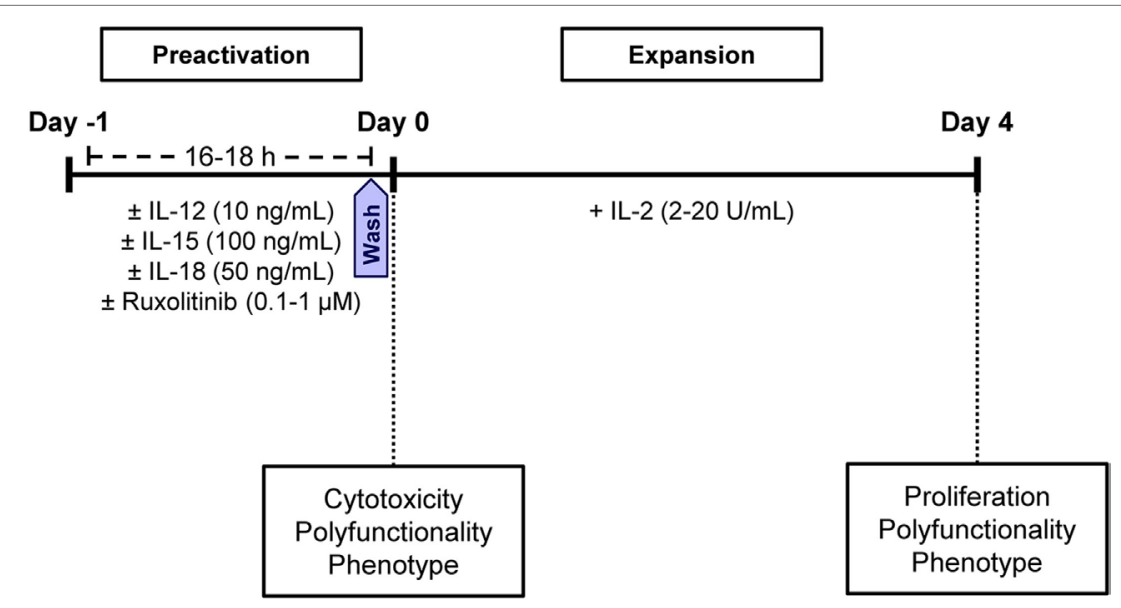

FIGURE 1 | Graphic representation showing the culture conditions of natural killer (NK) cells. During the preactivation phase (16 -18 h), cells were stimulated with different combinations of IL-12, IL-15, and IL-18 in the presence and absence of ruxolitinib. During the expansion phase, NK cells were cultured with IL-2 for 4 days. At the end of the preactivation and expansion phases, the phenotype and effector functions of NK cells were tested. 
phase (4 days in the presence of IL-2), cells were also stained with LIVE/DEAD ${ }^{\mathrm{TM}}$ kit to exclude dead cells. Finally, cells were washed twice and acquired in a FACSCanto II Flow Cytometer (BD Biosciences). NK cells were gated as CD3-CD56+. Flow cytometry data were analyzed with FlowJo v7.6.5 and v10.0.7 (TreeStar).

For phosphorylation assays, freshly isolated PBMCs were washed with PBS and plated into 96 well plates at $10^{6} \mathrm{cell} / \mathrm{mL}$ in cIMDM. Then, cells were stimulated, in the presence and absence of $0.1 \mu \mathrm{M}$ ruxolitinib, with cytokines [IL-12 (10 ng/mL), IL-15 (10 ng/mL), and IL-18 (50 ng/mL)] for $20 \mathrm{~min}$ at $37^{\circ} \mathrm{C}$ while they were stained for the surface markers CD3 and CD56. After the incubation, cells were harvested and washed with PBS before fixing them with the BD Cytofix buffer at $37^{\circ} \mathrm{C}$ for $10 \mathrm{~min}$. Cells were washed again two times and permeabilized with the BD Phosflow Perm buffer III for 30 min on ice. Next, they were incubated for $30 \mathrm{~min}$ on ice with specific labeled phospho-STAT5 (pSTAT5) Abs. Finally, cells were washed to remove unbound Abs and further acquired in a FACSCanto II Flow cytometer. Data were analyzed with FlowJo software.

\section{Statistical Analysis and Data Representation}

GraphPad Prism v6.01 and SPICE v5.3 (Vaccine Research Center, NIAID) (40) softwares were used for graphical representation and statistical analysis. Data were represented showing means \pm SEM. Prior to statistical analyses, data were tested for normal distribution with D'Agostino and Pearson normality test. If data were normally distributed, RM one-way ANOVA with the Greenhouse-Geisser correction was used to determine significant differences. Non-normal distributed data were compared with non-parametric Friedman test (for multiple comparisons) or non-parametric Wilcoxon matched-pairs signed rank test, as indicated in each figure legend. Differences between pie charts were determined with the non-parametric permutation test with 100,000 iterations. ${ }^{*} p<0.05,{ }^{* *} p<0.01,{ }^{* *} p<0.001$, $* * * * p<0.0001$.

\section{RESULTS}

\section{Cytotoxic Activity of Cytokine- Preactivated NK Cells Against K562 Target Cells}

As it has been previously reported, NK cells can be preactivated with different combinations of cytokines (41-43). CIML NK cells are generated by the preactivation for a short period of time with a cocktail of cytokines including IL-12, IL-15, and IL-18 $(25,28)$. In vitro, human CIML NK cells exhibit enhanced effector functions after a resting phase that could last for weeks $(27,28,30,44)$. In vivo, preclinical models have shown that IL-12/15/18preactivated NK cells exhibit sustained effector functions against established tumors (45). Importantly, adoptively transferred CIML NK cells (after $12-16 \mathrm{~h}$ of preactivation) have shown a clinical benefit in the treatment of patients with AML (27).

In order to study the contribution of each cytokine to the generation of CIML NK cells, we have analyzed the involvement of IL-12, IL-15, and IL-18 either alone or in different combinations. First, we tested the cytotoxic activity of human NK cells against K562 cancer cells, right after the preactivation phase. We demonstrated that cells stimulated for 16-18 h with IL-15 either alone or in combination with other cytokines exhibited the highest cytotoxic activity against K562 target cells (Figure 2A). Given that IL-15R acts through the Jak1/3 pathways and IL-12R involves signaling through Jak2 and Tyk2 pathways $(46,47)$, we investigated whether the presence of ruxolitinib (a specific Jak1/2 inhibitor) during the preactivation phase could affect the cytolytic potential of CIML NK cells. We first tested ruxolitinibmediated inhibition by determining the phosphorylation of STAT5, which is involved in the IL-15R signaling pathway (48). Our results showed a strong phosphorylation of STAT5 in NK cells stimulated with IL-12, IL-15, and IL-18 in the absence of ruxolitinib. However, the levels of STAT5 phosphorylation in cytokine-stimulated NK cells in the presence of ruxolitinib were similar to non-stimulated NK cells (Figure S1 in Supplementary Material). Since signaling through IL-15R is partially impaired when Jak1 is inhibited, we predicted that ruxolitinib will reduce the killing ability of CIML NK cells. To prove our assumption, during the preactivation phase, PBMCs were exposed or not to ruxolitinib. As expected, CIML NK cell cytotoxic activity was diminished when they were generated in the presence of ruxolitinib (Figure 2B). We also observed that control nonpreactivated NK cells exhibited a reduced cytotoxic activity, although not statistically significant, when they were incubated for $18 \mathrm{~h}$ with ruxolitinib.

\section{Polyfunctionality of Cytokine-Stimulated NK Cells}

To further analyze the effector functions of cytokine-stimulated NK cells, we next examined the contribution of each cytokine to NK cell polyfunctionality, which is defined by those cells that simultaneously produce multiple cytokines and degranulate $(49,50)$. To determine polyfunctionality, we measured the expression of the extracellular CD107a as a marker of degranulation (51), and the production of IFN $\gamma, \mathrm{TNF} \alpha$, and CCL3. Our results revealed that CIML NK cells are significantly the most polyfunctional cells and that IL-12+IL-18 is the only combination of cytokines that generate NK cells with a similar polyfunctional profile (Figure 3A). Furthermore, the frequency of NK cells that are non-functional gradually decreases as more cytokines are used for the preactivation, being the combination of IL-12 + IL-15 + IL-18 (i.e., CIML NK cells) the one with the lower percentage of non-functional cells (Figure 3A). These results indicate that each one of the three cytokines synergizes with the other two to generate CIML NK cells with enhanced polyfunctionality.

Afterward, we studied the polyfunctionality of CIML NK cells exposed to ruxolitinib during the preactivation phase. Since ruxolitinib reduces the cytotoxic activity of CIML NK cells (Figure 2B), we presumed that the polyfunctionality of these cells could also be affected in response to the preactivation with the three cytokines. In order to address this issue, two different concentrations of ruxolitinib were used $(0.1$ and $1 \mu \mathrm{M})$, which correspond to the serum levels found in treated patients $(52,53)$. 


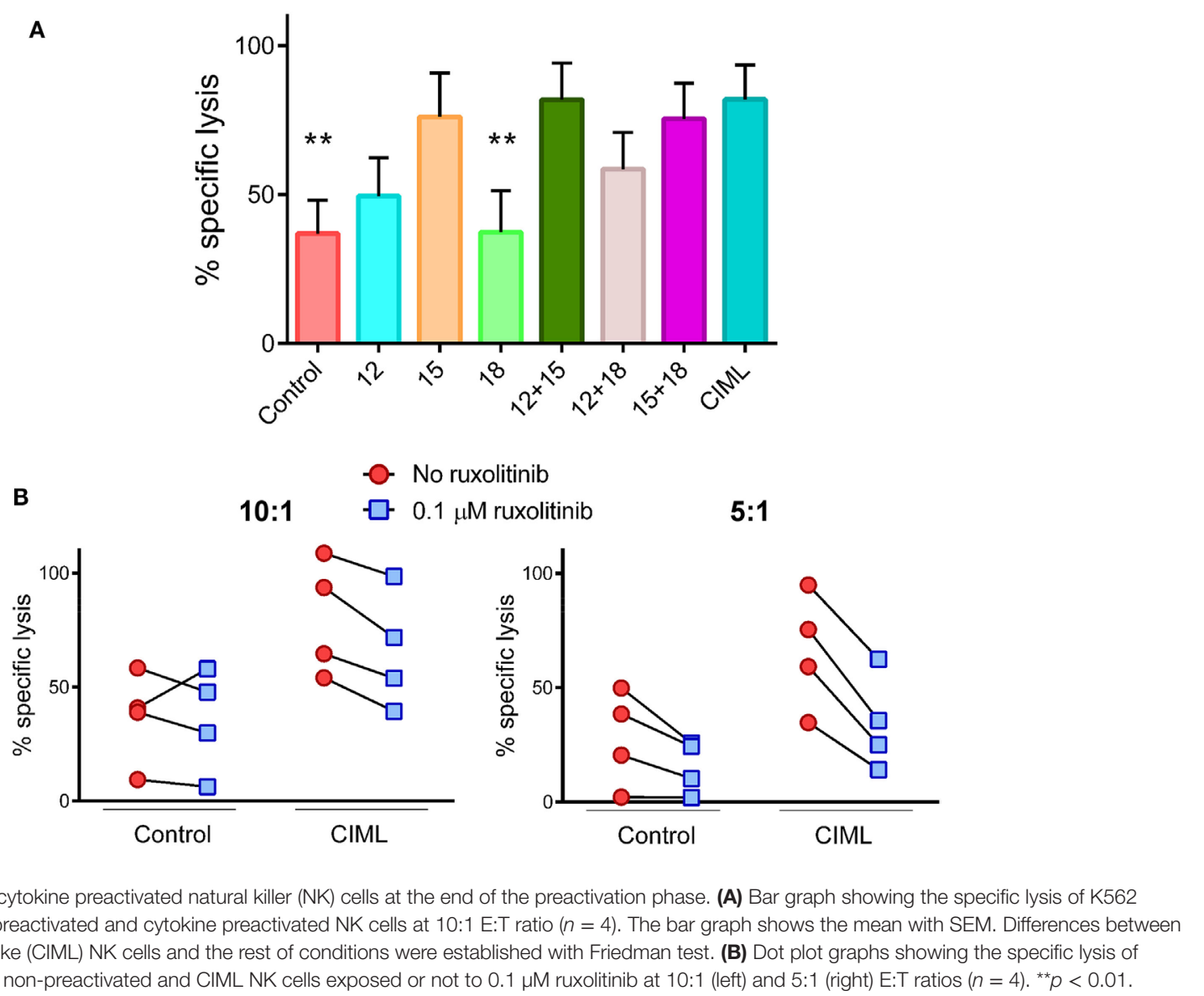

We observed that a concentration of $0.1 \mu \mathrm{M}$ ruxolitinib slightly reduces the polyfunctionality of CIML NK cells, while the higher dose $(1 \mu \mathrm{M})$ induces a significant reduction (Figure $3 \mathrm{~B}$ ). Of note, CIML NK cells exposed to both concentrations of ruxolitinib are significantly more polyfunctional than control nonpreactivated NK cells, indicating that part of the effect mediated by the combination of IL-12, IL-15, and IL-18 is independent of Jak1/2 (Figure 3B).

\section{Phenotype of CIML NK Cells}

In order to be suitable and effective for adoptive cell therapy, CIML NK cells must be able to traffic to the tumor site. This trafficking is to a large extent regulated by several chemokine and other homing receptors. Thus, in the context of hematological malignancies, we analyzed the expression of CD62L and CXCR4, two cell surface receptors that are required for homing to lymph nodes and bone marrow, respectively $(54,55)$. Additionally, we also studied the expression of IL-2R $\alpha$ (CD25), which conforms, along with the IL-2R $\beta \gamma$, the high-affinity receptor IL-2R $\alpha \beta \gamma$ that signals in response to picomolar concentrations of IL-2 (56). In line with the results obtained by other authors, ours showed that the expression of CD25 is specially increased when human NK cells are preactivated with IL-15 + IL-18 or IL-12 + IL-15 + IL-18 $(26,45,57)$ (Figure $4 A)$. Conversely, the expression of CXCR4 and the percentage of CD62L+ NK cells are reduced when they are preactivated. Interestingly, the expression of CXCR4 is specially reduced when NK cells are exposed to IL-15, either alone or in combination with other cytokines, indicating that IL-15 has the most relevant role in decreasing the cell surface expression of this chemokine receptor, while stimulation with IL-18 alone has little effect on CXCR4 expression (Figure 4A). Related to CD62L expression, we also observed that IL-15 is the most relevant cytokine for the decreased expression of this marker on CIML NK cells, while IL-12 alone has no effect (Figure 4A).

We also analyzed the effect of ruxolitinib on CIML NK cells phenotype. The expression of CXCR4 and the percentage of CD62L+ NK cells, which are decreased upon the stimulation with IL-12 + IL-15 + IL-18, are not severely affected by the inhibition of Jak1/2 during the preactivation phase. Contrariwise, we noted that the expression of CD25 tends to decrease in a ruxolitinib concentration-dependent manner; although the levels of this receptor are significantly higher in CIML NK cells generated in the presence of ruxolitinib than in control non-preactivated NK cells (Figure 4B).

\section{IL-2-Induced Proliferation of NK Cells Exposed to Different Combinations of Cytokines}

IL-2 has been widely used in cancer immunotherapy for both stimulation of autologous NK cells and activation/expansion of 
A

\begin{tabular}{|c|c|c|c|c|c|c|c|c|c|c|c|c|c|c|c|c|}
\hline \multicolumn{4}{|c|}{ Pie chart arc legend } & \multicolumn{4}{|c|}{ CD107a+ } & \multicolumn{3}{|c|}{ IFNץ+ } & \multicolumn{3}{|c|}{ TNF $\alpha+$} & \multicolumn{3}{|c|}{ CCL3+ } \\
\hline Pie slice & $\square$ & $\square$ & $\square$ & $\square$ & $\square$ & $\square$ & $\square$ & $\square$ & $\square$ & $\square$ & $\square$ & $\square$ & $\square$ & $\square$ & $\square$ & $\square$ \\
\hline CD107a & + & + & 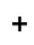 & + & & + & & + & - & . & - & - & . & - & - & - \\
\hline IFNy & + & + & + & + & & - & & - & + & + & + & + & - & - & - & - \\
\hline TNFa & + & + & - & - & + & + & - & - & + & + & - & - & + & + & - & - \\
\hline CCL3 & + & - & + & - & + & - & + & - & + & - & + & - & + & - & + & - \\
\hline
\end{tabular}

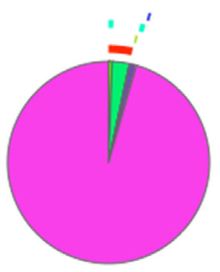

Control

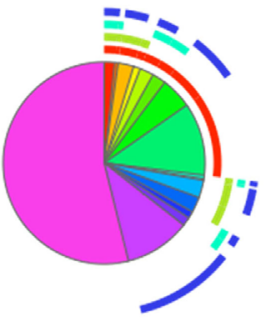

IL-12 + IL-15

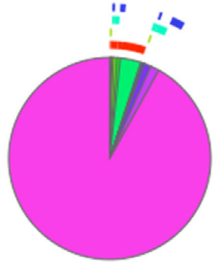

IL-12

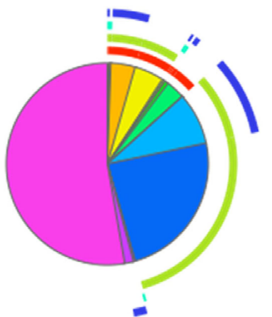

IL-12 + IL-18

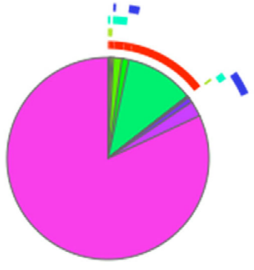

IL-15

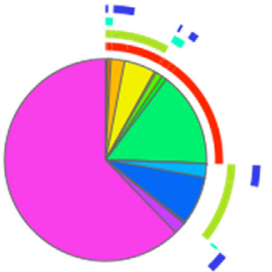

IL-15 + IL-18

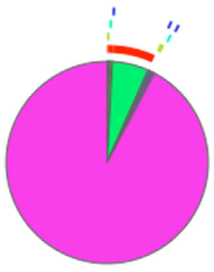

IL-18

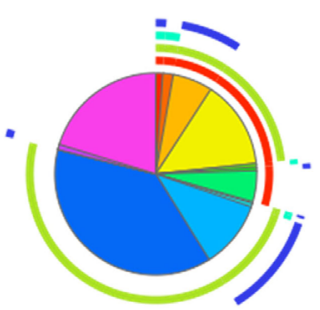

CIML

\begin{tabular}{|c|c|c|c|c|c|c|c|c|}
\hline & Control & IL-12 & |L-15 & IL-18 & IL-12 + IL-15 & IL-12 + IL-18 & IL-15 + IL-18 & CIML \\
\hline \multicolumn{9}{|l|}{ Control } \\
\hline IL-12 & 0.02886 & & & & & & & \\
\hline IL-15 & 0.02859 & 0.02876 & & & & & & \\
\hline IL-18 & 0.08602 & 0.19372 & 0.00752 & & & & & \\
\hline IL-12 + IL-15 & 0.02704 & 0.02902 & 0.02858 & 0.02900 & & & & \\
\hline IL-12 + IL-18 & 0.02743 & 0.01976 & 0.01931 & 0.01940 & 0.09990 & & & \\
\hline IL-15 + IL-18 & 0.02830 & 0.01954 & 0.01770 & 0.01930 & 0.17128 & 0.16643 & & \\
\hline CIML & 0.02947 & 0.02971 & 0.02920 & 0.02819 & 0.02907 & 0.08622 & 0.02878 & \\
\hline
\end{tabular}

B

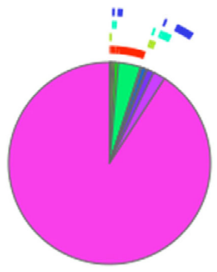

Control

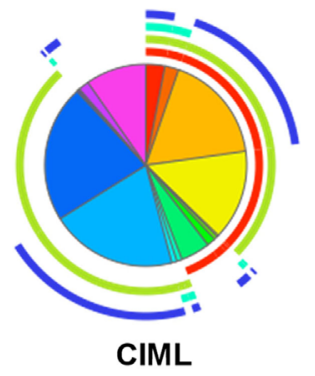

Control

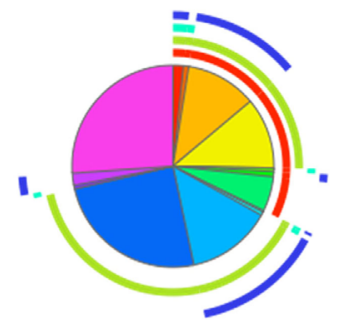

CIML

$+0.1 \mu \mathrm{M}$ ruxo

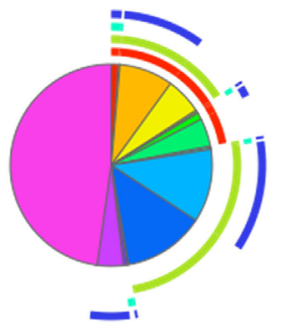

CIML

$+1 \mu \mathrm{M}$ ruxo

\begin{tabular}{|c|c|c|c|c|}
\hline & Control & CIML & $\mathrm{CIML}+0.1 \mu \mathrm{M}$ ruxo & $\mathrm{CIML}+1 \mu \mathrm{M}$ ruxo \\
\hline \multicolumn{5}{|l|}{ Control } \\
\hline CIML & 0.02799 & & & \\
\hline $\mathrm{CIML}+0.1 \mu \mathrm{M}$ ruxo & 0.02846 & 0.27747 & & \\
\hline $\mathrm{CIML}+1 \mu \mathrm{M}$ ruxo & 0.02811 & 0.04936 & 0.20199 & \\
\hline
\end{tabular}

FIGURE 3 | Polyfunctionality of cytokine preactivated natural killer (NK) cells after the preactivation phase. (A) Pie charts representing the percentages of control non-preactivated and cytokine preactivated NK cells expressing CD107a, interferon (IFN) $\gamma$, tumor necrosis factor (TNF) $\alpha$, and/or C-C motif chemokine ligand (CCL)3 $(n=4)$. (B) Pie charts representing the percentages of control non-preactivated and cytokine-induced memory-like (CIML) NK cells, and CIML NK cells preactivated in the presence of 0.1 and $1 \mu \mathrm{M}$ ruxolitinib, expressing CD107a, IFN $\gamma$, TNF $\alpha$, and/or CCL3 $(n=4)$. Differences between pie charts were established with nonparametric permutation test. The $p$-values are in the boxes below the pie charts. Significant differences are in the red cells. 


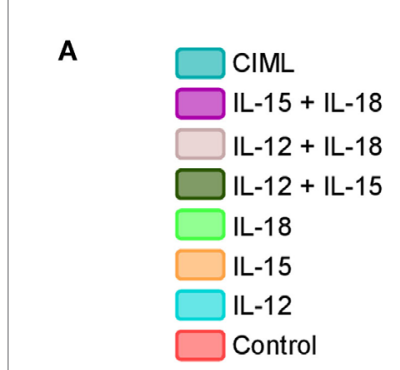

B
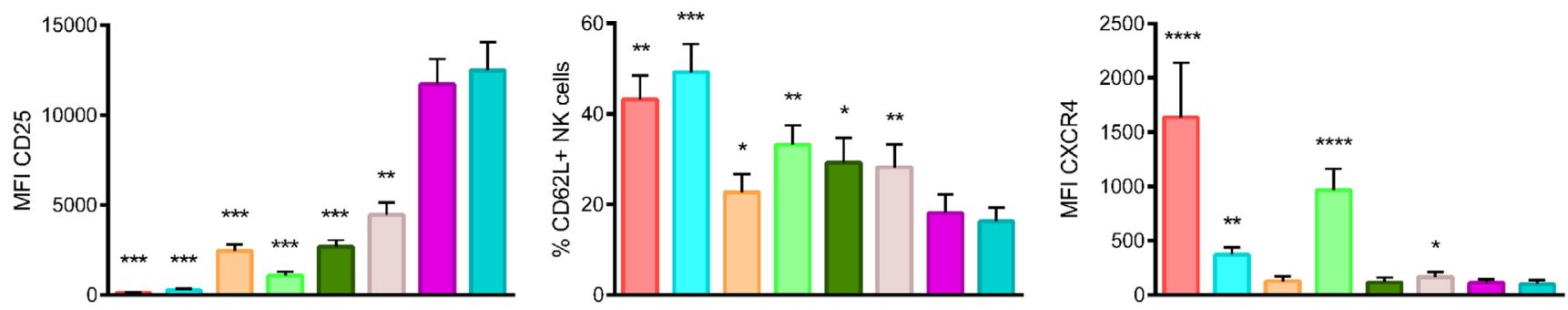
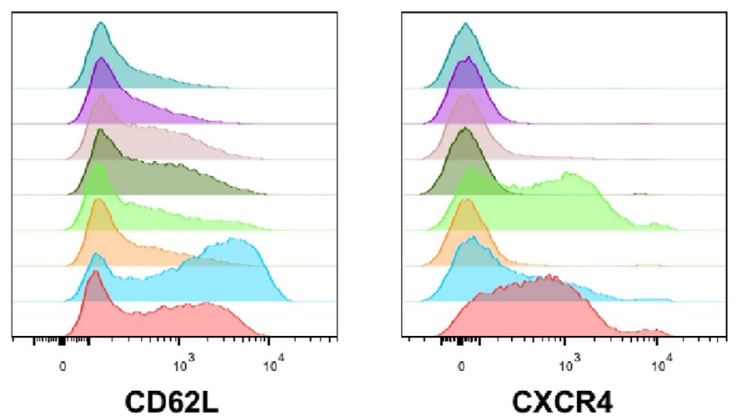

CD25
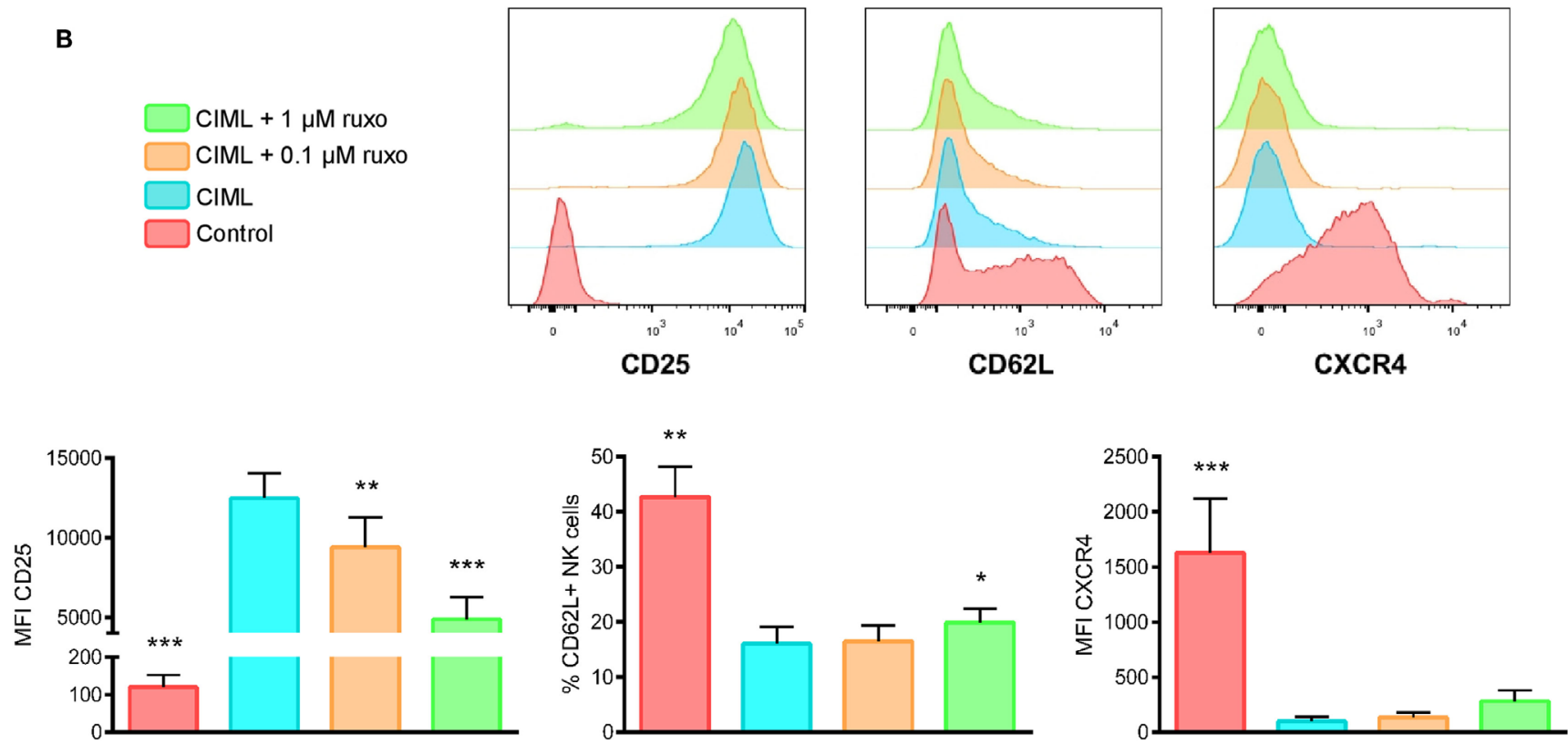

FIGURE 4 | Phenotype of cytokine preactivated natural killer (NK) cells after the preactivation phase. (A) Representative experiment (top) and bar graphs (bottom) showing the expression of CD25, CD62L, and CXCR4 on control non-preactivated and cytokine preactivated NK cells $(n=8)$. (B) A representative experiment (top) and bar graphs (bottom) showing the expression of CD25, CD62L and CXCR4 on control non-preactivated and cytokine-induced memory-like (CIML) NK cells, and CIML NK cells preactivated in the presence of 0.1 and $1 \mu \mathrm{M}$ ruxolitinib $(n=8)$. The bar graphs show the mean with SEM. Differences between CIML NK cells and the rest of conditions were established with RM one-way ANOVA with the Greenhouse-Geisser correction (for normally distributed data) or Friedman test (for non-normal distributed data). ${ }^{*} p<0.05,{ }^{* \star} p<0.01,{ }^{* \star *} p<0.001,{ }^{* \star \star *} p<0.0001$.

donor NK cells $(34,36,58)$. CIML NK cells (after 12-16 h of preactivation) were adoptively transferred to lymphodepleted patients with AML, and then, low doses of recombinant human IL-2 were administered to support memory-like NK cells expansion (27). We decided to study the proliferative potential of preactivated CIML NK cells in response to low concentrations of IL-2. In our experimental settings, after the preactivation phase, NK cells were washed and exposed to $20 \mathrm{U} / \mathrm{mL}$ of IL-2 for 4 days. We compared the proliferation of NK cells by calculating the division index (DI), defined as the average number of cell 
divisions that a cell in the original population has undergone (59). Our results showed that CIML NK cells proliferate significantly more than control non-preactivated NK cells and those exposed to just one cytokine alone (Figure 5A). Moreover, NK cells that were preactivated with the combination of two cytokines showed higher DI than those preactivated with just one cytokine, but lower DI than CIML NK cells, although is not statistically significant (Figure 5A).

We also studied whether the exposure to ruxolitinib during the preactivation phase could affect the posterior expansion of CIML NK cells in response to IL-2. Our findings revealed that Jak1/2 inhibition during the preactivation phase does not significantly reduce the proliferation of CIML NK cells (Figure 5B). Additionally, we cultured CIML NK cells with low or very low concentrations of IL-2 (20 and $2 \mathrm{U} / \mathrm{mL}$, respectively) to test the effect of limiting amounts of this cytokine during the expansion phase. As expected, a very low dose of IL-2 induced a smaller proliferative response of CIML NK cells, which was not affected by the presence of ruxolitinib during the preactivation phase (Figure 5C).

\section{Ruxolinib-Treated CIML NK Cells Recover Their Polyfunctionality After the Expansion Phase}

The presence of ruxolitinib during the preactivation phase significantly reduces the polyfunctionality of preactivated CIML NK cells (Figure 3B). We studied whether this reduction is maintained or not after an expansion phase of 4 days, in the presence of IL-2. NK cells were preactivated with IL-12, IL-15, and IL-18, with or without ruxolitinib. Then, cells were washed and exposed to low or very low concentrations of IL-2 for 4 days. After the expansion phase, we analyzed their polyfunctional profile in the absence and after encountering K562 cancer cells. First, as expected, NK cells cocultured with K562 target cells exhibited a significantly higher polyfunctional profile. Furthermore, CIML NK cells were more polyfunctional than control nonpreactivated NK cells when exposed to IL-2 for 4 days. Importantly, there are no statistically significant differences between CIML NK cells that were preactivated in the presence and absence of ruxolitinib (Figure 6), indicating that their polyfunctionality, both without and after encountering K562 tumor cells, is not substantially affected by the exposure to Jak $1 / 2$ inhibitor during the preactivation phase. These results indicate that the effect of ruxolitinib on the polyfunctionality of CIML NK cells during the preactivation phase is reversible, so that after the expansion with low and very low doses of IL-2 the consequences of exposure to this drug disappear. This can be explained by the fact that CIML NK cells generated in the presence of ruxolitinib still express enough levels of CD25 that allow them to respond to low doses of IL-2 (Figure 4B).

\section{Ruxolitinib Has No Severe Impact on the Expression of CD62L and CXCR4 Homing Receptors in Expanded CIML NK Cells}

Finally, we analyzed the expression of CD62L and CXCR4 homing receptors after the expansion phase. Our results showed that the percentage of CD62L+ NK cells (Figure 7, left panel) was similar between the three tested conditions (i.e., control non-preactivated and CIML NK cells exposed or not to ruxolitinib), while the expression of CXCR4 (Figure 7, right panel) was reduced when NK cells were preactivated, both in the presence and absence of the Jak1/2 inhibitor. Notably, although the concentration of IL-2 during the expansion phase had little or no effect on the percentage of CD62L+cells, the expression of CXCR4 was higher when cells were exposed to lower doses of IL-2, somehow suggesting that cell activation induces a downregulation of CXCR4 (Figure 7). Our findings revealed that the expression of CXCR4 after the expansion phase was partially affected by the concentration of IL-2, but not by the exposure of NK cells to ruxolitinib during the preactivation phase.

\section{DISCUSSION}

Natural killer cells play a pivotal role in the immunosurveillance of malignant cells $(1,2,33,60-62)$. They have become a promising tool in cancer immunotherapy with an increasing number of basic and translational studies focused on them, including those about CIML NK cells (2, 27-29, 32, 38, 45, 61, 63-66). Several studies have shed light on the in vivo antitumor properties of CIML NK cells and their potential in the treatment of AML $(27,45)$. However, a more extensive characterization of their effector functions, proliferative capacity and phenotype, of these cytokine preactivated NK cells, it is required in order to design the best immunotherapy. In our study, we sought to describe the synergistic effect that IL-12, IL-15, and IL-18 combinations have on the cytotoxicity, polyfunctionality, expression of homing receptors, and IL-2-induced proliferation of human NK cells in vitro. Moreover, we have tested the effect of ruxolitinib, a Jak1/2 inhibitor, in the generation of CIML NK cells, in an attempt to better understand the roles of IL-12R- and IL-15R-mediated signals during the preactivation phase.

Our data provide evidence of a major contribution of IL-15 to CIML NK cell-mediated cytotoxicity against K562 cancer cells. In line with our results, other authors have previously demonstrated that stimulation with IL-15 enhanced the cytotoxicity of NK cells against K562 targets, primary acute leukemic blasts, and rhabdomyosarcoma cell lines (67-70). The enhanced responses of IL-15-primed NK cells are the outcome of several factors, including the upregulation of several NK cell activating receptors and increased production of cytokines and cytotoxic proteins $(68,70-72)$.

Nevertheless, our functional analysis of CIML NK cells was not limited to their cytotoxic potential. We extended our study of these cells in an attempt to thoroughly investigate more effector functions. Our data revealed that cytokine preactivation reduces the percentage of quadruple negative (CD107a- IFN $\gamma-$ $\mathrm{TNF} \alpha-\mathrm{CCL} 3-) \mathrm{NK}$ cells, and that this percentage is even lower as more cytokines are used during the preactivation phase. In this line, the combination of IL-12 + IL-15 + IL-18 (i.e., CIML NK cells) shows the lower percentage of cells negative for the tested functions, supporting the idea that the synergistic effect of these three cytokines is required to endow NK cells 


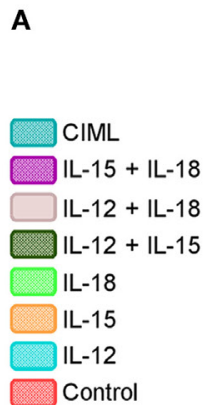

$\mathrm{CIML}+1 \mu \mathrm{M}$ ruxo $\mathrm{CIML}+0.1 \mu \mathrm{M}$ ruxo

CIML

Control

B
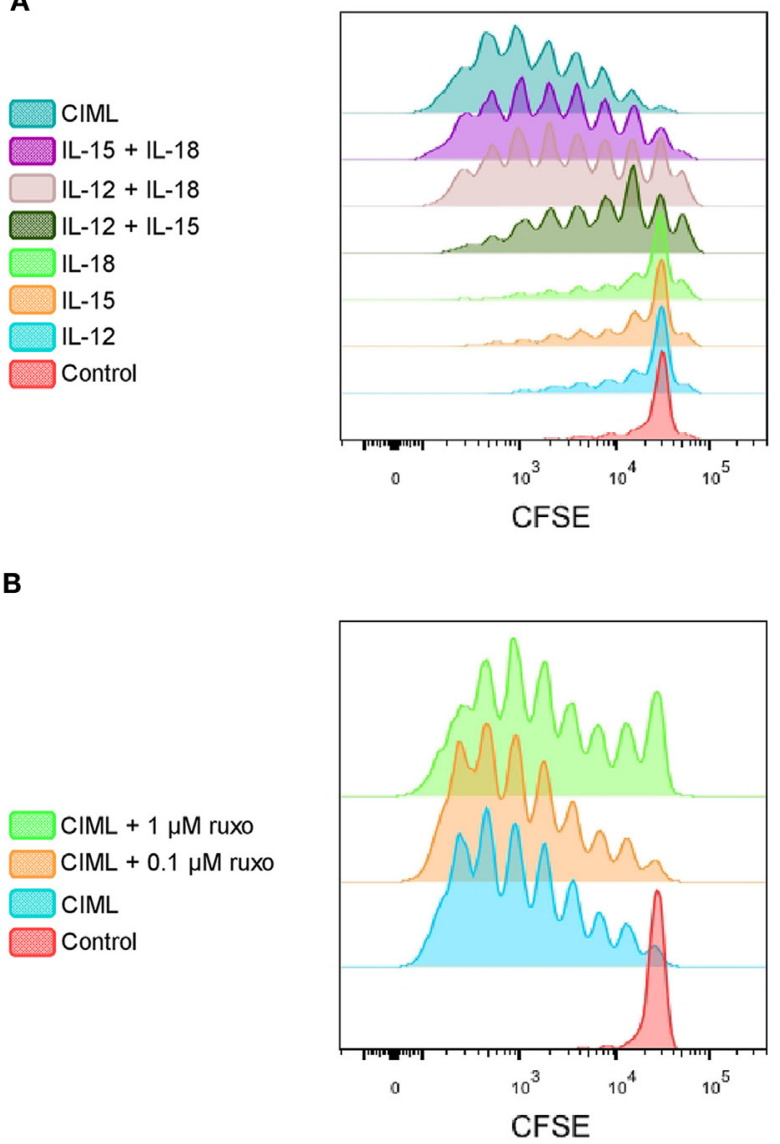

C

$\mathrm{CIML}+1 \mu \mathrm{M}$ ruxo (2)

CIML + $1 \mu \mathrm{M}$ ruxo (20)

CIML (2)

CIML (20)

Control (2)

Control (20)

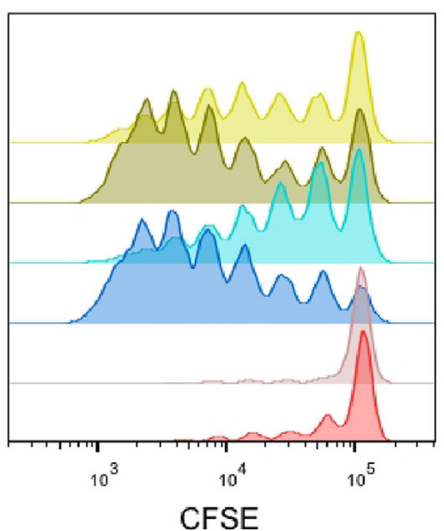

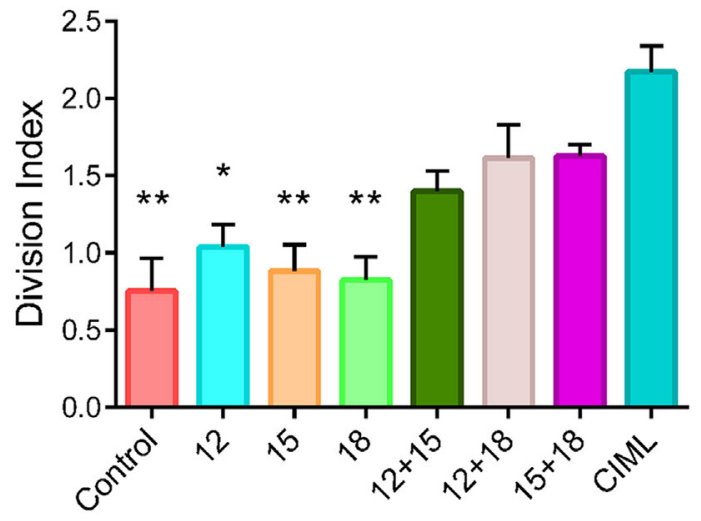
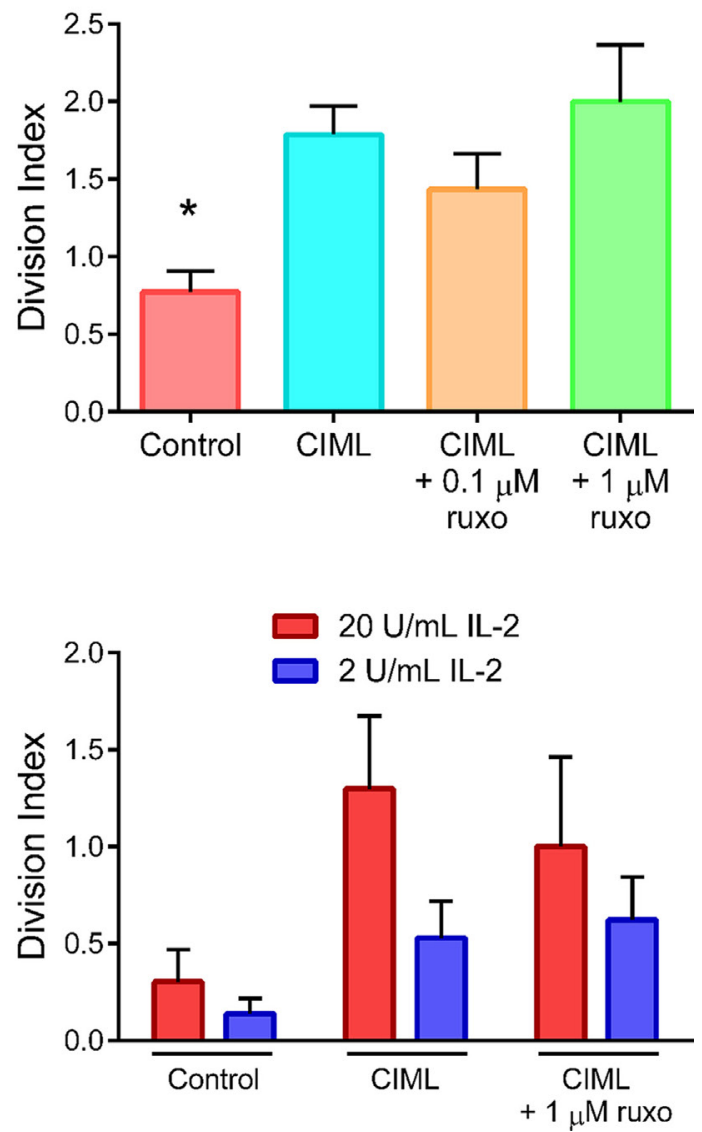

FIGURE 5 | IL-2-induced proliferation of cytokine preactivated natural killer (NK) cells at the end of the expansion phase of 4 days. (A) Histograms of a representative experiment (left) and bar graphs showing the division index (DI) (right) of control non-preactivated and cytokine preactivated NK cells $(n=6)$. (B) A representative experiment (left) and bar graphs showing the DI (right) of control non-preactivated and cytokine-induced memory-like (CIML) NK cells, and CIML NK cells preactivated in the presence 0.1 and $1 \mu \mathrm{M}$ ruxolitinib $(n=5)$. (C) A representative experiment (left) and bar graphs showing the DI (right) of control non-preactivated and CIML NK cells, preactivated in the presence and absence of $1 \mu \mathrm{M}$ ruxolitinib, exposed to 2 or $20 \mathrm{U} / \mathrm{mL} \mathrm{IL}-2 \mathrm{during}$ the expansion phase $(n=5)$. The bar graphs show the mean with SEM. Differences between CIML NK cells and the rest of conditions were established with Friedman test. ${ }^{*} p<0.05$, ${ }^{* *} p<0.01$.

the best polyfunctional profile. Each one of the three cytokines contributes to the final phenotypical and functional features that CIML NK cells exhibit. For example, in this context, it has been previously reported that IL-12-mediated signals are essential for the generation of human NK cells with enhanced effector functions after restimulation $(30,73)$. Chaix et al. have described the 


\begin{tabular}{|lcccccccc|}
\hline \multicolumn{2}{l}{ Pie chart arc legend } & \multicolumn{2}{c}{ CD107a+ } & \multicolumn{3}{l|}{ IFNy+ $^{+}$} & TNFa+ \\
\hline Pie slice & $\square$ & $\square$ & $\square$ & $\square$ & $\square$ & $\square$ & $\square$ & $\square$ \\
CD107a & + & + & + & + & - & - & - & - \\
IFNy & + & + & - & - & + & + & - & - \\
TNFa & + & - & + & - & + & - & + & - \\
\hline
\end{tabular}
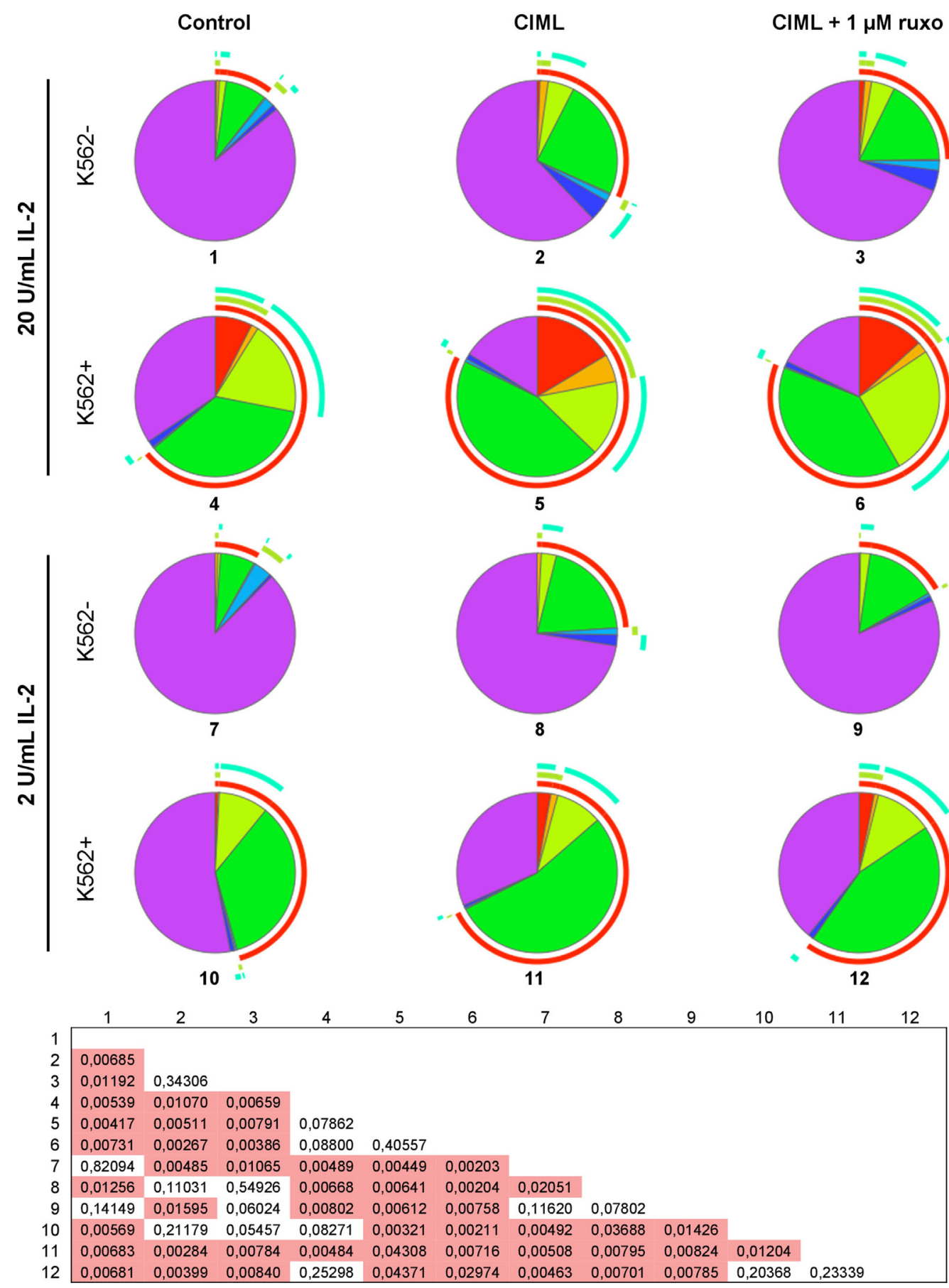

FIGURE 6 | Polyfunctionality of cytokine-induced memory-like (CIML) natural killer (NK) cells after the expansion phase. Pie charts represent the percentages of control non-preactivated and CIML NK cells, preactivated in the presence and absence of $1 \mu \mathrm{M}$ ruxolitinib, expressing CD107a, IFN $\gamma$, and/or TNF $\alpha$. Cells were exposed to $2 \mathrm{U} / \mathrm{mL}$ (lower six pie charts) or $20 \mathrm{U} / \mathrm{mL}$ (upper six pie charts) of IL-2 during the expansion phase of 4 days, and then washed and incubated with or without K562 cells for $6 \mathrm{~h}(n=6)$. Differences between pie charts were established with non-parametric permutation test. The $p$ values are in the box below the pie charts. Significant differences are in the red cells. 


\section{$\square 20 \mathrm{U} / \mathrm{mL}$ IL-2 \\ $\square 2 \mathrm{U} / \mathrm{mL} \mathrm{IL}-2$}
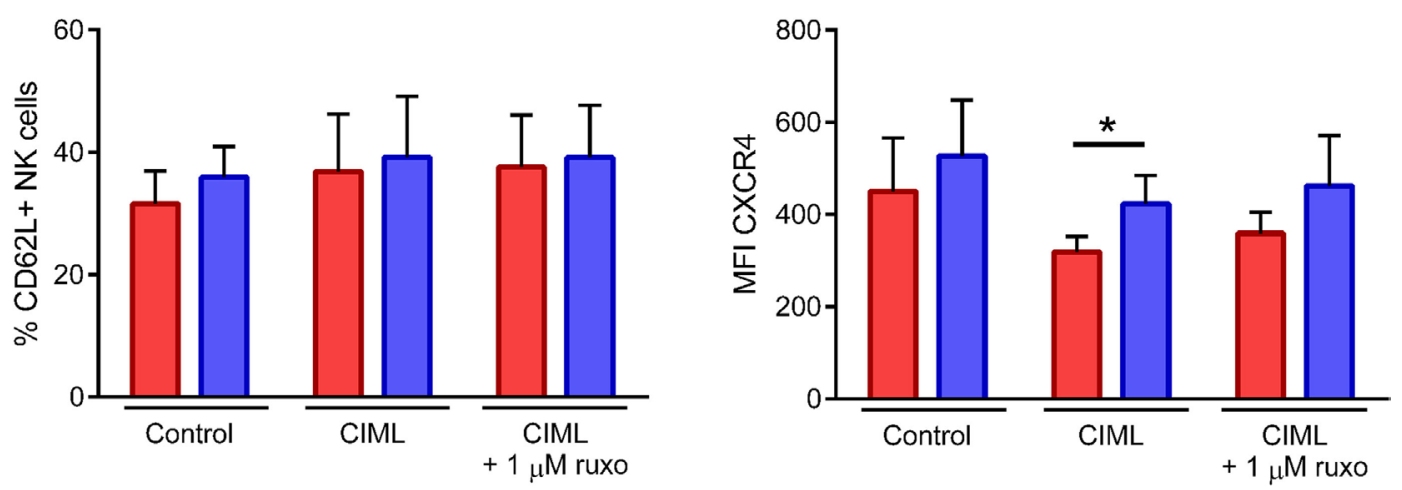

FIGURE 7 | CD62L and CXCR4 expression of cytokine-induced memory-like (CIML) natural killer (NK) cells after the expansion phase. Bar graphs showing the percentage of CD62L+ NK cells and the expression (MFI, median fluorescence intensity) of CXCR4 in control non-preactivated and CIML NK cells, preactivated in the presence and absence of $1 \mu \mathrm{M}$ ruxolitinib, exposed to 2 or $20 \mathrm{U} / \mathrm{mL} \| \mathrm{L}-2$ during the expansion phase $(n=6)$. Bar graphs show the mean with SEM. Statistical differences were established with Wilcoxon matched-pairs signed rank test. ${ }^{*} p<0.05$.

cooperation between IL-12 and IL-18, where signaling through IL-18R/MyD88/IRAK4 pathway was required for IFN $\gamma$ production by NK cells in response to IL-12 (74). Accordingly, other authors have proposed IL-18 as the key cytokine that primes NK cells to respond to other cytokines (57). IL-15 can be also used to prime NK cells, although the improved functionality persists no longer than $72 \mathrm{~h}$ after stimulation (70), in comparison with CIML NK cells that show sustained antitumor activity and can be detected up to 3 months after adoptive transfer in mice $(27,29,45)$.

The small number of donors in our study could be a limitation since there are several factors that we have not considered. For instance, HCMV infection status has a significant influence on cytokine responsiveness of NK cells. Goodier et al. reported that the production of IFN $\gamma$ and the expression of CD107a and CD25 by cytokine-stimulated NK cells were different between HCMV + and HCMV - individuals (75). In addition, NK cell responses are also strongly influenced by KIR-HLA interactions. Although we have not analyzed the KIR repertoire, several studies have revealed the impact of cytokines on KIR cell surface expression. Ewen et al. have found that the activation of NK cells with IL-12/15/18 led to a decreased expression of KIR2DL1, KIR2DL2/L3, and KIR3DL1. They found that this downregulation was not detectable before $36 \mathrm{~h}$ of cytokinestimulation and that the most pronounced downregulation was observed around 48-60 h after stimulation (63). Other authors have also showed the capacity of IL-2 to modulate the KIR repertoire $(76,77)$. However, Romee et al. reported that allogeneic adoptive transferred CIML NK cells showed a similar production of IFN $\gamma$ in both KIR-mismatched and -matched situations against primary AML blasts (27). On the other hand, Horowitz et al. have shown that a dimorphism at position -21 of the HLA-B leader sequence has a great impact on the NK cell IFN $\gamma$ response upon IL-12/15 stimulation (78). In the future, it will be of great interest to study KIR-HLA interactions, HCMV status, and other factors in our experimental settings.

Cytokine pre-stimulation induces phenotypic changes that may influence, to a greater or lesser extent, trafficking and proliferation of NK cells. We found differential expression of CXCR4, CD62L, and CD25 markers following cytokine stimulation, which depend on the interleukin combination we used to preactivate the NK cells. Our results show that CXCR4 is drastically downregulated when IL-15 is present in the cytokine cocktail, or a combination of two or three cytokines is used during the preactivation phase. However, these differences in the expression of CXCR4 between control non-preactivated and CIML NK cells are not maintained for a long time. As shown, after the expansion phase in the presence of $20 \mathrm{U} / \mathrm{mL}$ of IL-2, the expression levels of CXCR4 is reduced, both in control non-preactivated and CIML NK cells (Figure 7). Likewise, it has been previously reported that NK cells stimulated with high doses $(1,000 \mathrm{U} / \mathrm{mL}$ ) of IL-2 (whose receptor shares the $\beta$ and $\gamma$ subunits with IL-15R) for 5 days decreased CXCR4 expression levels and homing/accumulation to the bone marrow (54). Since CIML NK cells are being used for the treatment of hematological malignancies (clinical trials NCT01898793, NCT03068819, and NCT02782546), it would be preferable that they express higher levels of CXCR4 in order to improve the trafficking to the bone marrow. As we have demonstrated, expanding CIML NK cells with very low doses of IL-2 $(2 \mathrm{U} / \mathrm{mL})$ resulted in a higher expression of this marker in comparison to those cells exposed to $20 \mathrm{U} / \mathrm{mL}$, thus highlighting the impact of the dose of IL-2 given during the expansion phase. Nevertheless, Romee et al. have shown that, after 7 days, adoptively transferred human CIML NK cells are able to localize in key hematopoietic tissues (i.e., bone marrow, spleen, and blood) in similar numbers compared to control non-preactivated NK cells in NSG mice, even in the presence 
of IL-2. Furthermore, they have reported that at day 8 postinfusion, CIML NK cells are present at large percentages in the bone marrow of AML patients who were also treated with IL-2 (27). Thus, although the reduced expression of CXCR4 seems not to be a limiting factor for homing CIML NK cells to the bone marrow, it is not clear if the administration of even lower doses of IL-2 may increase the trafficking of CIML NK cells. Additional in vivo studies should be performed to clarify this issue. It would be very interesting to comprehensively study CXCR4 regulation. For example, to investigate whether cytokine stimulation has some effects on the proteins that regulate its surface expression and endocytosis (i.e., filamin A and $\beta$-arrestin-1) (79). Moreover, several studies have shown that CXCR4 expression can be upregulated with glucocorticoids $(80,81)$, TGF- $\beta 1(82,83)$, or the BCR-ABL tyrosine kinase inhibitors imatinib and nilotinib (84). Hence, preactivation of NK cells with IL-12, IL-15, and IL-18 should be tested in the presence of these drugs.

Our results also show that CD62L is downregulated on CIML NK cells after cytokine stimulation, which is in accordance with the results obtained by others $(29,85,86)$. In contrast, Romee et al. have reported that the expression of CD62L is upregulated on CIML NK cells after a resting period of 7 days (27), while in our experiments, NK cells were being stimulated with IL-2. The main responsibility of CD62L downregulation is A Disintegrin and Metalloprotease 17 (ADAM17) (86). Thus, the use of specific inhibitors of ADAM17 during the preactivation phase could inhibit CD62L downregulation, as it has been recently demonstrated on NK cells stimulated with IL-12 + IL-18 (86). In a broader context, matrix metalloproteases inhibitors are able to impede CD16 and CD62L downregulation following NK cell activation (50,86-88). Therefore, if the objective is to increase the expression of CD62L, it would be interesting to explore the generation of CIML NK cells while inhibiting matrix metalloproteases. Furthermore, matrix metalloprotease inhibition promotes NK cell polyfunctionality in antibody-based antitumor immunotherapy $(50,86)$.

The expression of CD25 is outstandingly upregulated when NK cells are stimulated for 16-18 h with IL-15 + IL-18 or IL-12 + IL-15 + IL-18, which is in agreement with the results obtained from other authors $(26,57)$. Moreover, Leong et al. have described that IL-2 stimulates the proliferation of NK cells preactivated with IL-15, IL-12 + IL-18, or IL-15 + IL-18 and have linked the expression of CD25 to IL-2-induced proliferation in those cells (26). We have investigated the proliferation of NK cells preactivated with all the combinations of IL-12, IL-15, and IL-18, and found that CIML NK cells have the highest DI. However, the combination of two cytokines also has a significant impact on NK cell proliferation.

In addition to the contribution of each cytokine to NK cell phenotype and effector functions, we have also examined the effect of Jak1/2 inhibition during the preactivation phase. Schönberg et al. reported that ruxolitinib impairs K562 killing of IL-2 preactivated NK cells (89). Our protocol is somehow different from the one that Schönberg et al. have followed. In our experiments, NK cells were exposed simultaneously to ruxolitinib and cytokines, and thoroughly washed after the preactivation phase to remove them from the medium. Nevertheless, we have also shown that ruxolitinib has a noticeable effect on the functionality of CIML NK cells just after the preactivation phase, reducing their cytotoxic activity against K562 targets and their polyfunctionality in a dose-dependent manner. It has been described that Jak1/2 inhibition prevented IL-2 induced upregulation of granzyme B, NKp46, NKG2D, and CD69 (89). Also, $\mathrm{Jak} 1 / 2$ inhibition reduced degranulation and IFN $\gamma$ production of NK cells stimulated with monocyte-derived dendritic cells (90). These findings suggest that ruxolitinib diminished NK cell functionality, which are in agreement with the reduced cytotoxicity against K562 target cells of ruxolitinib-exposed control non-preactivated and CIML NK cells. However, the effects of ruxolitinib on degranulation and specific killing are reversible (89). Accordingly, we have measured the polyfunctionality after 4 days of expansion phase and found that CIML NK cells that were exposed to the highest dose of ruxolitinib $(1 \mu \mathrm{M})$ showed no differences in their polyfunctional profile compared to non ruxolitinib treated CIML NK cells, reinforcing the finding that the effects of ruxolitinib are reversible.

Jak1/2 inhibition does not prevent the downregulation of homing receptors CD62L and CXCR4 in CIML NK cells. Furthermore, the high CD25 expression on CIML NK cells is significantly reduced when they are preactivated in the presence of $1 \mu \mathrm{M}$ ruxolitinib. To evaluate its impact, we analyzed IL-2-induced proliferation and found no significant differences between CIML NK cells exposed or not to ruxolitinib. Therefore, we conclude that, even though the expression of CD25 is reduced, it is sufficient to promote the proliferation of CIML NK cells exposed to low doses of IL-2. Indeed, the concentration of IL-2 during the expansion phase, rather than Jak1/2 inhibition, could be a limiting factor for NK cell proliferation, as we have demonstrated. Altogether, our results suggest that the exposure of CIML NK cells to ruxolitinib during the preactivation phase could mitigate the initial impact that these highly activated NK cells, producing very high amounts of cytokines, may have on the patient right after the cell infusion.

\section{ETHICS STATEMENT}

All subjects provided written and signed informed consent in accordance with the Declaration of Helsinki. The protocol was approved by the Basque Ethics Committee for Clinical Research.

\section{AUTHOR CONTRIBUTIONS}

IT designed and performed experiments, analyzed and interpreted the data, designed the figures, and wrote the manuscript. IM wrote the manuscript and analyzed data. IO, AG and JG performed experiments, analyzed and interpreted the data. AO and JV participated in the analysis and interpretation of the data. OZ performed experiments, participated in the design of the study and interpreted the data. FB conceived and designed the study, interpreted the data, and wrote the manuscript. All the authors critically reviewed, edited and approved the final manuscript. 


\section{ACKNOWLEDGMENTS}

The authors thank all of the healthy donors who participated in the study and the staff of the Basque Biobank for Research (http:// www.biobancovasco.org) and the Basque Center for Transfusion and Human Tissues. This study was supported by grants from Health Department, Basque Government (2013111034 and 2017222005), Basque Foundation for Research and InnovationEiTB Maratoia (BIO14/TP/003) and AECC-Spanish Association Against Cancer (PROYE16074BORR). Joana Vitallé is recipient of a predoctoral contract funded by the Department of Education, Language Policy and Culture, Basque Government (PRE_2017_2_0242). Joana Vitallé and Iñigo Terrén are recipients

\section{REFERENCES}

1. Caligiuri MA. Human natural killer cells. Blood (2008) 112:461-9. doi:10.1182/blood-2007-09-077438

2. Fang F, Xiao W, Tian Z. NK cell-based immunotherapy for cancer. Semin Immunol (2017) 31:37-54. doi:10.1016/j.smim.2017.07.009

3. Freud AG, Mundy-Bosse BL, Yu J, Caligiuri MA. The broad spectrum of human natural killer cell diversity. Immunity (2017) 47:820-33. doi:10.1016/j. immuni.2017.10.008

4. Vivier E, Raulet DH, Moretta A, Caligiuri MA, Zitvogel L, Lanier LL, et al. Innate or adaptive immunity? The example of natural killer cells. Science (2011) 331:44-9. doi:10.1126/science.1198687

5. Long EO, Kim HS, Liu D, Peterson ME, Rajagopalan S. Controlling natural killer cell responses: integration of signals for activation and inhibition. Annu Rev Immunol (2013) 31:227-58. doi:10.1146/annurev-immunol-020711-075005

6. Watzl C, Long EO. Signal transduction during activation and inhibition of natural killer cells. In: Coligan JE, Margulies DH, Shevach EM, Strober W, editors. Current Protocols in Immunology. Hoboken, NJ, USA: John Wiley \& Sons, Inc. (2010). Unit 11.9B p.

7. Borrego F, Kabat J, Kim D-K, Lieto L, Maasho K, Peña J, et al. Structure and function of major histocompatibility complex (MHC) class I specific receptors expressed on human natural killer (NK) cells. Mol Immunol (2002) 38:637-60. doi:10.1016/S0161-5890(01)00107-9

8. Lankry D, Simic H, Klieger Y, Levi-Schaffer F, Jonjic S, Mandelboim O. Expression and function of CD300 in NK Cells. J Immunol (2010) 185: 2877-86. doi:10.4049/jimmunol.0903347

9. Barrow AD, Edeling MA, Trifonov V, Luo J, Goyal P, Bohl B, et al. Natural killer cells control tumor growth by sensing a growth factor. Cell (2018) 172: 534-48.e19. doi:10.1016/j.cell.2017.11.037

10. Dimitrova M, Zenarruzabeitia O, Borrego F, Simhadri VR. CD300c is uniquely expressed on CD56 bright natural killer cells and differs from CD300a upon ligand recognition. Sci Rep (2016) 6:23942. doi:10.1038/srep23942

11. O'Leary JG, Goodarzi M, Drayton DL, von Andrian UH. T cell- and B cellindependent adaptive immunity mediated by natural killer cells. Nat Immunol (2006) 7:507-16. doi:10.1038/ni1332

12. Sun JC, Beilke JN, Lanier LL. Adaptive immune features of natural killer cells. Nature (2009) 457:557-61. doi:10.1038/nature07665

13. Gillard GO, Bivas-Benita M, Hovav A-H, Grandpre LE, Panas MW, Seaman MS, et al. Thyl+ NK [corrected] cells from vaccinia virus-primed mice confer protection against vaccinia virus challenge in the absence of adaptive lymphocytes. PLoS Pathog (2011) 7:e1002141. doi:10.1371/journal.ppat.1002141

14. Paust S, Gill HS, Wang B-Z, Flynn MP, Moseman EA, Senman B, et al. Critical role for the chemokine receptor CXCR6 in NK cell-mediated antigen-specific memory of haptens and viruses. Nat Immunol (2010) 11: 1127-35. doi:10.1038/ni.1953

15. Reeves RK, Li H, Jost S, Blass E, Li H, Schafer JL, et al. Antigen-specific NK cell memory in rhesus macaques. Nat Immunol (2015) 16:927-32. doi:10.1038/ ni. 3227

16. Gumá M, Angulo A, Vilches C, Gómez-Lozano N, Malats N, López-Botet M. Imprint of human cytomegalovirus infection on the NK cell receptor repertoire. Blood (2004) 104:3664-71. doi:10.1182/blood-2004-05-2058 of a fellowship from the Jesús de Gangoiti Barrera Foundation (FJGB15/008 and FJGB17/003). Olatz Zenarruzabeitia is recipient of a postdoctoral contract funded by "Instituto de Salud Carlos III-Contratos Sara Borrell 2017 (CD17/00128)" and the European Social Fund (ESF)-The ESF invests in your future. Francisco Borrego is an Ikerbasque Research Professor, Ikerbasque, Basque Foundation for Science.

\section{SUPPLEMENTARY MATERIAL}

The Supplementary Material for this article can be found online at https://www.frontiersin.org/articles/10.3389/fimmu.2018.00737/ full\#supplementary-material.

17. López-Botet M, Muntasell A, Vilches C. The CD94/NKG2C+ NK-cell subset on the edge of innate and adaptive immunity to human cytomegalovirus infection. Semin Immunol (2014) 26:145-51. doi:10.1016/j.smim. 2014.03.002

18. Muntasell A, Vilches C, Angulo A, López-Botet M. Adaptive reconfiguration of the human NK-cell compartment in response to cytomegalovirus: a different perspective of the host-pathogen interaction. Eur J Immunol (2013) 43:1133-41. doi:10.1002/eji.201243117

19. Cichocki F, Cooley S, Davis Z, DeFor TE, Schlums H, Zhang B, et al. CD56dimCD57+NKG2C+ NK cell expansion is associated with reduced leukemia relapse after reduced intensity HCT. Leukemia (2016) 30:456-63. doi:10.1038/leu.2015.260

20. Costa-Garcia M, Vera A, Moraru M, Vilches C, López-Botet M, Muntasell A. Antibody-mediated response of NKG2Cbright NK cells against human cytomegalovirus. J Immunol (2015) 194:2715-24. doi:10.4049/jimmunol.1402281

21. Lee J, Zhang T, Hwang I, Kim A, Nitschke L, Kim M, et al. Epigenetic modification and antibody-dependent expansion of memory-like NK cells in human cytomegalovirus-infected individuals. Immunity (2015) 42:431-42. doi:10.1016/j.immuni.2015.02.013

22. Redondo-Pachón D, Crespo M, Yélamos J, Muntasell A, Pérez-Sáez MJ, Pérez-Fernández S, et al. Adaptive NKG2C+ NK cell response and the risk of cytomegalovirus infection in kidney transplant recipients. J Immunol (2017) 198:94-101. doi:10.4049/jimmunol.1601236

23. Schlums H, Cichocki F, Tesi B, Theorell J, Beziat V, Holmes TD, et al. Cytomegalovirus infection drives adaptive epigenetic diversification of NK cells with altered signaling and effector function. Immunity (2015) 42:443-56. doi:10.1016/j.immuni.2015.02.008

24. Zhang T, Scott JM, Hwang I, Kim S. Cutting edge: antibody-dependent memory-like NK cells distinguished by FcR $\gamma$ deficiency. J Immunol (2013) 190:1402-6. doi:10.4049/jimmunol.1203034

25. Cooper MA, Elliott JM, Keyel PA, Yang L, Carrero JA, Yokoyama WM. Cytokine-induced memory-like natural killer cells. Proc Natl Acad Sci U S A (2009) 106:1915-9. doi:10.1073/pnas.0813192106

26. Leong JW, Chase JM, Romee R, Schneider SE, Sullivan RP, Cooper MA, et al. Preactivation with IL-12, IL-15, and IL-18 induces CD25 and a functional high-affinity IL-2 receptor on human cytokine-induced memory-like natural killer cells. Biol Blood Marrow Transplant (2014) 20:463-73. doi:10.1016/j. bbmt.2014.01.006

27. Romee R, Rosario M, Berrien-Elliott MM, Wagner JA, Jewell BA, Schappe T, et al. Cytokine-induced memory-like natural killer cells exhibit enhanced responses against myeloid leukemia. Sci Transl Med (2016) 8:357ra123. doi:10.1126/scitranslmed.aaf2341

28. Romee R, Schneider SE, Leong JW, Chase JM, Keppel CR, Sullivan RP, et al Cytokine activation induces human memory-like NK cells. Blood (2012) 120:4751-60. doi:10.1182/blood-2012-04-419283

29. Hüber CM, Doisne J-M, Colucci F. IL-12/15/18-preactivated NK cells suppress GvHD in a mouse model of mismatched hematopoietic cell transplantation. Eur J Immunol (2015) 45:1727-35. doi:10.1002/eji.201445200

30. Simhadri VR, Mariano JL, Zenarruzabeitia O, Seroogy CM, Holland SM, Kuehn HS, et al. Intact IL-12 signaling is necessary for the generation of human natural killer cells with enhanced effector function after restimu- 
lation. J Allergy Clin Immunol (2014) 134:1190.e-3.e. doi:10.1016/j.jaci. 2014.06.006

31. Wagner JA, Berrien-Elliott MM, Rosario M, Leong JW, Jewell BA, Schappe T, et al. Cytokine-induced memory-like differentiation enhances unlicensed natural killer cell antileukemia and Fc $\gamma$ RIIIa-triggered responses. Biol Blood Marrow Transplant (2017) 23:398-404. doi:10.1016/j.bbmt.2016.11.018

32. Borrego F, Larrucea S, Solana R, Tarazona R. Editorial: NK cell-based cancer immunotherapy. Front Immunol (2016) 7:249. doi:10.3389/fimmu. 2016.00249

33. Childs RW, Carlsten M. Therapeutic approaches to enhance natural killer cell cytotoxicity against cancer: the force awakens. Nat Rev Drug Discov (2015) 14:487-98. doi:10.1038/nrd4506

34. Cooley S, Parham P, Miller JS. Strategies to activate NK cells to prevent relapse and induce remission following hematopoietic stem cell transplantation. Blood (2018) 131:1053-62. doi:10.1182/blood-2017-08-752170

35. Ruggeri L, Capanni M, Urbani E, Perruccio K, Shlomchik WD, Tosti A, et al. Effectiveness of donor natural killer cell alloreactivity in mismatched hematopoietic transplants. Science (2002) 295:2097-100. doi:10.1126/science. 1068440

36. Bachanova V, Cooley S, Defor TE, Verneris MR, Zhang B, McKenna DH, et al. Clearance of acute myeloid leukemia by haploidentical natural killer cells is improved using IL-2 diphtheria toxin fusion protein. Blood (2014) 123:3855-63. doi:10.1182/blood-2013-10-532531

37. Pérez-Martínez A, Fernández L, Valentín J, Martínez-Romera I, Corral MD, Ramírez M, et al. A phase I/II trial of interleukin-15 - stimulated natural killer cell infusion after haplo-identical stem cell transplantation for pediatric refractory solid tumors. Cytotherapy (2015) 17:1594-603. doi:10.1016/j. jcyt.2015.07.011

38. Ruggeri L, Parisi S, Urbani E, Curti A. Alloreactive natural killer cells for the treatment of acute myeloid leukemia: from stem cell transplantation to adoptive immunotherapy. Front Immunol (2015) 6:479. doi:10.3389/fimmu. 2015.00479

39. Herrera L, Salcedo JM, Santos S, Vesga MÁ, Borrego F, Eguizabal C. OP9 feeder cells are superior to M2-10B4 cells for the generation of mature and functional natural killer cells from umbilical cord hematopoietic progenitors. Front Immunol (2017) 8:755. doi:10.3389/fimmu.2017.00755

40. Roederer M, Nozzi JL, Nason MC. SPICE: exploration and analysis of postcytometric complex multivariate datasets. Cytometry A (2011) 79:167-74. doi:10.1002/cyto.a.21015

41. Cooper MA, Fehniger TA, Ponnappan A, Mehta V, Wewers MD, Caligiuri MA. Interleukin-1beta costimulates interferon-gamma production by human natural killer cells. Eur J Immunol (2001) 31:792-801. doi:10.1002/1521-4141 (200103)31:3<792::AID-IMMU792>3.0.CO;2-U

42. Fehniger TA, Shah MH, Turner MJ, VanDeusen JB, Whitman SP, Cooper MA, et al. Differential cytokine and chemokine gene expression by human NK cells following activation with IL-18 or IL-15 in combination with IL-12: implications for the innate immune response. J Immunol (1999) 162:4511-20. doi:10.4049/jimmunol.178.7.4194

43. Yu J, Wei M, Becknell B, Trotta R, Liu S, Boyd Z, et al. Pro- and antiinflammatory cytokine signaling: reciprocal antagonism regulates interferon-gamma production by human natural killer cells. Immunity (2006) 24:575-90. doi:10.1016/j.immuni.2006.03.016

44. Simhadri VR, Dimitrova M, Mariano JL, Zenarruzabeitia O, Zhong W, Ozawa $\mathrm{T}$, et al. A human anti-M2 antibody mediates antibody-dependent cell-mediated cytotoxicity (ADCC) and cytokine secretion by resting and cytokine-preactivated natural killer (NK) cells. PLoS One (2015) 10:e0124677. doi:10.1371/journal.pone.0124677

45. Ni J, Miller M, Stojanovic A, Garbi N, Cerwenka A. Sustained effector function of IL-12/15/18-preactivated NK cells against established tumors. J Exp Med (2012) 209:2351-65. doi:10.1084/jem.20120944

46. Bacon CM, McVicar DW, Ortaldo JR, Rees RC, O'Shea JJ, Johnston JA. Interleukin 12 (IL-12) induces tyrosine phosphorylation of JAK2 and TYK2: differential use of Janus family tyrosine kinases by IL-2 and IL-12. J Exp Med (1995) 181:399-404. doi:10.1084/jem.181.1.399

47. Fehniger TA, Caligiuri MA. Interleukin 15: biology and relevance to human disease. Blood (2001) 97:14-32. doi:10.1182/blood.V97.1.14

48. Wu Y, Tian Z, Wei H. Developmental and functional control of natural killer cells by cytokines. Front Immunol (2017) 8:930. doi:10.3389/fimmu.2017. 00930
49. Narayanan S, Silva R, Peruzzi G, Alvarez Y, Simhadri VR, Debell K, et al. Human Th1 cells that express $\mathrm{CD} 300 \mathrm{a}$ are polyfunctional and after stimulation up-regulate the T-box transcription factor eomesodermin. PLoS One (2010) 5:e10636. doi:10.1371/journal.pone.0010636

50. Zhou Q, Gil-Krzewska A, Peruzzi G, Borrego F. Matrix metalloproteinases inhibition promotes the polyfunctionality of human natural killer cells in therapeutic antibody-based anti-tumour immunotherapy. Clin Exp Immunol (2013) 173:131-9. doi:10.1111/cei.12095

51. Alter G, Malenfant JM, Altfeld M. CD107a as a functional marker for the identification of natural killer cell activity. J Immunol Methods (2004) 294: 15-22. doi:10.1016/j.jim.2004.08.008

52. Heine A, Held SAE, Daecke SN, Wallner S, Yajnanarayana SP, Kurts C, et al. The JAK-inhibitor ruxolitinib impairs dendritic cell function in vitro and in vivo. Blood (2013) 122:1192-202. doi:10.1182/blood-2013-03-484642

53. Shilling AD, Nedza FM, Emm T, Diamond S, McKeever E, Punwani N, et al. Metabolism, excretion, and pharmacokinetics of [14C]INCB018424, a selective Janus tyrosine kinase 1/2 inhibitor, in humans. Drug Metab Dispos (2010) 38:2023-31. doi:10.1124/dmd.110.033787

54. Beider K, Nagler A, Wald O, Franitza S, Dagan-Berger M, Wald H, et al. Involvement of CXCR4 and IL-2 in the homing and retention of human NK and NK T cells to the bone marrow and spleen of NOD/SCID mice. Blood (2003) 102:1951-8. doi:10.1182/blood-2002-10-3293

55. Olson JA, Zeiser R, Beilhack A, Goldman JJ, Negrin RS. Tissue-specific homing and expansion of donor NK cells in allogeneic bone marrow transplantation. J Immunol (2009) 183:3219-28. doi:10.4049/jimmunol. 0804268

56. Rickert M, Wang X, Boulanger MJ, Goriatcheva N, Garcia KC. The structure of interleukin-2 complexed with its alpha receptor. Science (2005) 308:1477-80. doi:10.1126/science.1109745

57. Nielsen CM, Wolf A-S, Goodier MR, Riley EM. Synergy between common $\gamma$ chain family cytokines and IL-18 potentiates innate and adaptive pathways of NK cell activation. Front Immunol (2016) 7:101. doi:10.3389/ fimmu.2016.00101

58. Granzin M, Wagner J, Köhl U, Cerwenka A, Huppert V, Ullrich E. Shaping of natural killer cell antitumor activity by ex vivo cultivation. Front Immunol (2017) 8:458. doi:10.3389/fimmu.2017.00458

59. Roederer M. Interpretation of cellular proliferation data: avoid the panglossian. Cytometry A (2011) 79:95-101. doi:10.1002/cyto.a.21010

60. Cerwenka A, Lanier LL. Natural killer cell memory in infection, inflammation and cancer. Nat Rev Immunol (2016) 16:112-23. doi:10.1038/nri.2015.9

61. Dahlberg CIM, Sarhan D, Chrobok M, Duru AD, Alici E. Natural killer cellbased therapies targeting cancer: possible strategies to gain and sustain antitumor activity. Front Immunol (2015) 6:605. doi:10.3389/fimmu.2015.00605

62. Fehniger TA, Cooper MA. Harnessing NK cell memory for cancer immunotherapy. Trends Immunol (2016) 37:877-88. doi:10.1016/j.it.2016.09.005

63. Ewen E-M, Pahl JHW, Miller M, Watzl C, Cerwenka A. KIR downregulation by IL-12/15/18 unleashes human NK cells from KIR/HLA-I inhibition and enhances killing of tumor cells. Eur J Immunol (2018) 48:355-65. doi:10.1002/ eji.201747128

64. Lusty E, Poznanski SM, Kwofie K, Mandur TS, Lee DA, Richards CD, et al. IL-18/IL-15/IL-12 synergy induces elevated and prolonged IFN- $\gamma$ production by ex vivo expanded NK cells which is not due to enhanced STAT4 activation. Mol Immunol (2017) 88:138-47. doi:10.1016/j.molimm.2017. 06.025

65. Pittari G, Filippini P, Gentilcore G, Grivel J-C, Rutella S. Revving up natural killer cells and cytokine-induced killer cells against hematological malignancies. Front Immunol (2015) 6:230. doi:10.3389/fimmu.2015.00230

66. Zenarruzabeitia O, Vitallé J, Astigarraga I, Borrego F. Natural killer cells to the attack: combination therapy against neuroblastoma. Clin Cancer Res (2017) 23:615-7. doi:10.1158/1078-0432.CCR-16-2478

67. Boerman GH, van Ostaijen-ten Dam MM, Kraal KCJM, Santos SJ, Ball LM, Lankester AC, et al. Role of NKG2D, DNAM-1 and natural cytotoxicity receptors in cytotoxicity toward rhabdomyosarcoma cell lines mediated by resting and IL-15-activated human natural killer cells. Cancer Immunol Immunother (2015) 64:573-83. doi:10.1007/s00262-015-1657-9

68. Sanchez-Correa B, Bergua JM, Pera A, Campos C, Arcos MJ, Bañas H, et al. In vitroculture with interleukin-15 leads to expression of activating receptors and recovery of natural killer cell function in acute myeloid leukemia patients. Front Immunol (2017) 8:931. doi:10.3389/fimmu.2017.00931 
69. van Ostaijen-ten Dam MM, Prins H-J, Boerman GH, Vervat C, Pende D, Putter $\mathrm{H}$, et al. Preparation of cytokine-activated NK cells for use in adoptive cell therapy in cancer patients: protocol optimization and therapeutic potential. J Immunother (2016) 39:90-100. doi:10.1097/CJI.0000000000000110

70. Wagner JA, Rosario M, Romee R, Berrien-Elliott MM, Schneider SE, Leong JW, et al. CD56bright NK cells exhibit potent antitumor responses following IL-15 priming. J Clin Invest (2017) 127:4042-58. doi:10.1172/JCI90387

71. Szczepanski MJ, Szajnik M, Welsh A, Foon KA, Whiteside TL, Boyiadzis M. Interleukin-15 enhances natural killer cell cytotoxicity in patients with acute myeloid leukemia by upregulating the activating NK cell receptors. Cancer Immunol Immunother (2010) 59:73-9. doi:10.1007/s00262-009-0724-5

72. Vendrame E, Fukuyama J, Strauss-Albee DM, Holmes S, Blish CA. Mass cytometry analytical approaches reveal cytokine-induced changes in natural killer cells. Cytometry B Clin Cytom (2017) 92:57-67. doi:10.1002/cyto.b.21500

73. Sun JC, Madera S, Bezman NA, Beilke JN, Kaplan MH, Lanier LL. Proinflammatory cytokine signaling required for the generation of natural killer cell memory. J Exp Med (2012) 209:947-54. doi:10.1084/jem.20111760

74. Chaix J, Tessmer MS, Hoebe K, Fuséri N, Ryffel B, Dalod M, et al. Cutting edge: priming of NK cells by IL-18. J Immunol (2008) 181:1627-31. doi:10.4049/ jimmunol.181.3.1627

75. Goodier MR, Rodriguez-Galan A, Lusa C, Nielsen CM, Darboe A, Moldoveanu AL, et al. Influenza vaccination generates cytokine-induced memory-like NK cells: impact of human cytomegalovirus infection. J Immunol (2016) 197:313-25. doi:10.4049/jimmunol.1502049

76. de Rham C, Ferrari-Lacraz S, Jendly S, Schneiter G, Dayer J-M, Villard J. The proinflammatory cytokines IL-2, IL-15 and IL-21 modulate the repertoire of mature human natural killer cell receptors. Arthritis Res Ther (2007) 9:R125. doi:10.1186/ar2336

77. Huenecke S, Zimmermann SY, Kloess S, Esser R, Brinkmann A, Tramsen L, et al. IL-2-driven regulation of NK cell receptors with regard to the distribution of CD16+ and CD16- subpopulations and in vivo influence after haploidentical NK cell infusion. J Immunother (2010) 33:200-10. doi:10.1097/ CJI.0b013e3181bb46f7

78. Horowitz A, Djaoud Z, Nemat-Gorgani N, Blokhuis J, Hilton HG, Béziat V, et al. Class I HLA haplotypes form two schools that educate NK cells in different ways. Sci Immunol (2016) 1:eaag1672-1672. doi:10.1126/sciimmunol. aag 1672

79. Bernardini G, Antonangeli F, Bonanni V, Santoni A. Dysregulation of chemokine/chemokine receptor axes and NK cell tissue localization during diseases. Front Immunol (2016) 7:402. doi:10.3389/fimmu.2016.00402

80. Moustaki A, Argyropoulos KV, Baxevanis CN, Papamichail M, Perez SA. Effect of the simultaneous administration of glucocorticoids and IL-15 on human NK cell phenotype, proliferation and function. Cancer Immunol Immunother (2011) 60:1683-95. doi:10.1007/s00262-011-1067-6

81. Okutsu M, Ishii K, Niu K, Nagatomi R. Cortisol is not the primary mediator for augmented CXCR4 expression on natural killer cells after acute exercise. J Appl Physiol (2014) 117:199-204. doi:10.1152/japplphysiol.00176.2014
82. Castriconi R, Dondero A, Bellora F, Moretta L, Castellano A, Locatelli F, et al. Neuroblastoma-derived TGF- $\beta 1$ modulates the chemokine receptor repertoire of human resting NK cells. J Immunol (2013) 190:5321-8. doi:10.4049/ jimmunol.1202693

83. Inngjerdingen M, Damaj B, Maghazachi AA. Expression and regulation of chemokine receptors in human natural killer cells. Blood (2001) 97:367-75. doi:10.1182/blood.V97.2.367

84. Bellora F, Dondero A, Corrias MV, Casu B, Regis S, Caliendo F, et al. Imatinib and nilotinib off-target effects on human NK cells, monocytes, and M2 macrophages. J Immunol (2017) 199:1516-25. doi:10.4049/jimmunol.1601695

85. Lin S-J, Chen J-Y, Kuo M-L, Hsiao H-S, Lee P-T, Huang J-L. Effect of Interleukin-15 on CD11b, CD54, and CD62L expression on natural killer cell and natural killer T-like cells in systemic lupus erythematosus. Mediators Inflamm (2016) 2016:9675861. doi:10.1155/2016/9675861

86. Romee R, Foley B, Lenvik T, Wang Y, Zhang B, Ankarlo D, et al. NK cell CD16 surface expression and function is regulated by a disintegrin and metalloprotease-17 (ADAM17). Blood (2013) 121:3599-608. doi:10.1182/ blood-2012-04-425397

87. Borrego F, Lopez-Beltran A, Peña J, Solana R. Downregulation of Fc gamma receptor IIIA alpha (CD16-II) on natural killer cells induced by anti-CD16 $\mathrm{mAb}$ is independent of protein tyrosine kinases and protein kinase C. Cell Immunol (1994) 158:208-17. doi:10.1006/cimm.1994.1268

88. Peruzzi G, Femnou L, Gil-Krzewska A, Borrego F, Weck J, Krzewski K, et al. Membrane-type 6 matrix metalloproteinase regulates the activation-induced downmodulation of CD16 in human primary NK cells. J Immunol (2013) 191:1883-94. doi:10.4049/jimmunol.1300313

89. Schönberg K, Rudolph J, Vonnahme M, Parampalli Yajnanarayana S, Cornez I, Hejazi M, et al. JAK inhibition impairs NK cell function in myeloproliferative neoplasms. Cancer Res (2015) 75:2187-99. doi:10.1158/0008-5472. CAN-14-3198

90. Curran SA, Shyer JA, St Angelo ET, Talbot LR, Sharma S, Chung DJ, et al. Human dendritic cells mitigate NK-cell dysfunction mediated by nonselective JAK1/2 blockade. Cancer Immunol Res (2017) 5:52-60. doi:10.1158/23266066.CIR-16-0233

Conflict of Interest Statement: The authors declare that the research was conducted in the absence of any commercial or financial relationships that could be construed as a potential conflict of interest.

Copyright (c) 2018 Terrén, Mikelez, Odriozola, Gredilla, González, Orrantia, Vitallé, Zenarruzabeitia and Borrego. This is an open-access article distributed under the terms of the Creative Commons Attribution License (CC BY). The use, distribution or reproduction in other forums is permitted, provided the original author(s) and the copyright owner are credited and that the original publication in this journal is cited, in accordance with accepted academic practice. No use, distribution or reproduction is permitted which does not comply with these terms. 